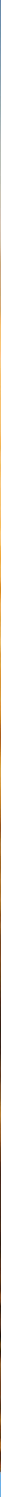

\title{
Cadmium in soil, crops and resultant dietary exposure
}

Rietra, R.P.J.J., G. Mol, I.M.C.M. Rietjens, P.F.A.M. Römkens

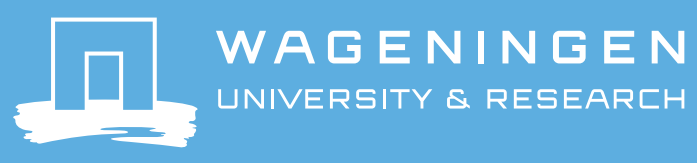





\section{Cadmium in soil, crops and resultant dietary exposure}

Rietra, R.P.J.J. ${ }^{1}$, G. Mol $^{1}$, I.M.C.M. Rietjens ${ }^{2}$, P.F.A.M. Römkens ${ }^{1}$

1 Wageningen Environmental Research

2 Wageningen University \& Research, Toxicology

This research was funded by OCP group.

Wageningen Environmental Research

Wageningen, January 2017

Report 2784

ISSN 1566-7197 
Rietra, R.P.J.J., G. Mol, I.M.C.M. Rietjens, and P.F.A.M. Römkens, 2017. Cadmium in soil, crops and resultant dietary exposure. Wageningen, Wageningen Environmental Research, Report 2784. 40 pp.; 7 fig.; 14 tab.; 74 ref.

The WHO and FAO jointly concluded in 2010 that exposure to cadmium through diet is below the provisional tolerable weekly intake of $5.8 \mu \mathrm{g} \mathrm{Cd} / \mathrm{kg}$ body weight per week. In Europe, however, EFSA $(2009,2012)$ has reduced the recommended tolerable level of cadmium in the diet to $2.5 \mu \mathrm{g} / \mathrm{kg} \mathrm{b.w}$. per week. Based on actual consumption patterns and levels of Cadmium in food stuffs EFSA estimated the total dietary exposure in Europe at, on average, $2.04 \mu \mathrm{g} / \mathrm{kg} \mathrm{b.w.} \mathrm{per} \mathrm{week,} \mathrm{which} \mathrm{is} \mathrm{below} \mathrm{the}$ reduced limit. However, the average exposure for infants and the $95^{\text {th }}$ percentile exposure for adults was estimated to be in excess of the reduced TWI, which led EFSA to conclude that there was a need to reduce intake of cadmium via dietary exposure.

As part of the revision of Fertiliser Regulations (EU2003/2003) a maximum level of Cadmium in phosphorus fertiliser has been proposed by EU in 2016 which not only facilitates trade between EU Member States but also reduces cadmium accumulation in soil and, presumably, contamination of food and water. Supply of Cadmium via P fertilisers is one of the main sources of Cadmium loads to arable soils. Due to the transfer of Cadmium from soil to crops via uptake, and subsequent consumption of such crops, dietary exposure partly depends on the Cadmium content in soil. However, at present it is unclear to what extent a reduction of Cadmium levels in phosphorus fertiliser will affect exposure of human beings through reduction of Cadmium in food products.

In this report a preliminary assessment is made of the contribution of Cadmium in European soils to the total intake of Cadmium via food. The assessment takes into account that not all food is grown on soil or is of EU origin, and the impact of reducing Cadmium levels in soil based on existing models that relate soil Cadmium to Cadmium in food crops. Based on the limited data available it is estimated that approximately $55 \%$ of the total dietary intake of $\mathrm{Cd}$ is related to Cadmium soil in the EU. A reduction of Cadmium in soil by $50 \%$ is estimated to result in a reduction of the total dietary intake by $18 \%$. Based on a basic calculation, Cadmium limits for $\mathrm{P}$ fertilisers are only expected to have a small impact on Cadmium levels in soils on time scales between 20 to 50 years. Considering the even smaller response in crop uptake to such limited changes in Cadmium levels in soil, it is therefore likely that a reduction of Cadmium levels in fertilisers will only marginally lower the Cadmium dietary exposure in Europe. More accurate estimates of such changes depend, among others, on the variability of Cadmium levels in soil, uptake patterns by crops and climatic variations all of which have not been considered here.

Keywords: Cd, fertiliser, exposure, food, soil

The pdf file is free of charge and can be downloaded at http://dx.doi.org/10.18174/403611 or via the website www.wur.nl/environmental-research (scroll down to Publications - Wageningen Environmental Research reports). Wageningen Environmental Research does not deliver printed versions of the Wageningen Environmental Research reports.

2017 Wageningen Environmental Research (an institute under the auspices of the Stichting Wageningen Research), P.O. Box 47, 6700 AA Wageningen, The Netherlands, T +31(0)317 4807 00, E info.alterra@wur.nl, www.wur.nl/environmental-research. Wageningen Environmental Research is part of Wageningen University \& Research.

- Acquisition, duplication and transmission of this publication is permitted with clear acknowledgement of the source.

- Acquisition, duplication and transmission is not permitted for commercial purposes and/or monetary gain.

- Acquisition, duplication and transmission is not permitted of any parts of this publication for which the copyrights clearly rest with other parties and/or are reserved.

Wageningen Environmental Research assumes no liability for any losses resulting from the use of the research results or recommendations in this report.

Wageningen Environmental Research Report 2784 | ISSN 1566-7197

Photo cover: Shutterstock 


\section{Contents}

1

$\begin{array}{ll}\text { The exposure chain } & 7\end{array}$

$\begin{array}{lll}2.1 & \text { Exposure of humans to Cadmium } & 7\end{array}$

2.1.1 Cadmium concentrations in food products 7

2.1.2 Food consumption data and exposure to Cadmium $\quad 8$

2.2 Cadmium: from crop to food product $\quad 11$

2.2.1 The effect of international commodity markets and trade $\quad 11$

2.2.2 Pathways from crops to animal products $\quad 15$

2.2.3 The effects of food processing 16

$\begin{array}{lll}2.3 & \text { Cadmium transfer from soil to crop } & 17\end{array}$

2.3.1 Predicting Cadmium levels in crops based on soil Cadmium concentrations17

2.3.2 Regional differences in Cadmium levels in soils and crops 19

2.3.3 Predicting effect of lowering EU soil Cadmium concentrations on Cadmium exposure

$\begin{array}{lll}2.4 & \text { Sources of Cadmium in soil } & 23\end{array}$

3.1 Conclusions $\quad 26$

3.2 Recommendations and uncertainties $\quad 29$

$\begin{array}{ll}\text { References } & \mathbf{3 0}\end{array}$

$\begin{array}{lll}\text { Annex } 1 & \text { Soil-plant transfer functions } & 34\end{array}$

Annex 2 Effect of different Cadmium soil levels for Cadmium in crop products $\quad 35$

Annex $3 \quad$ Reflection on the approach by Smolders and Six (2013) 36 



\section{Introduction}

Currently, a revision of the European Union's (EU's) Fertilisers Regulation (EU, 2003) has been drafted as part of the EU's Circular Economy Package (CEP)(EU, 2016). The new regulation may have considerable impact on the availability, applicability and pricing of existing Phosphorous (P) fertilisers across Europe. The driving factor behind this revision is to provide uniform trade regulations for fertilisers with regard to minimum required nutrient content and maximum allowed contaminant content. As such, setting maximum allowable levels of heavy metals will contribute to protecting the sustainability of soil use and, hence, quality of crops and surface water quality.

At present, however, there is considerable debate on the magnitude and expected impact of the acceptable levels of various contaminants, including Cadmium (Cd). The most recent European Commission proposal (from $7^{\text {th }}$ September 2016) includes a limit on Cd and other metals within a wide range of organic and inorganic fertilisers. For $\mathrm{Cd}$ in inorganic fertilisers with a $\mathrm{P}$ content of less than $5 \% \mathrm{P}$ (expressed as diphosphorus pentoxide $\left(\mathrm{P}_{2} \mathrm{O}_{5}\right)$ equivalent), the proposed limit is $3 \mathrm{mg} \mathrm{Cd} / \mathrm{kg} \mathrm{dry}$ matter. For inorganic fertilisers with a $\mathrm{P}$ content of more than $5 \%$ (expressed as $\mathrm{P}_{2} \mathrm{O}_{5}$ equivalent; i.e. most regular $P$ fertilisers), an initial limit of $60 \mathrm{mg} \mathrm{Cd} / \mathrm{kg} \mathrm{P}_{2} \mathrm{O}_{5}$ has been proposed, which will be further reduced to $40 \mathrm{mg} \mathrm{Cd} / \mathrm{kg} \mathrm{P}_{2} \mathrm{O}_{5}$ within three years, and $20 \mathrm{mg} \mathrm{Cd} / \mathrm{kg} \mathrm{P}_{2} \mathrm{O}_{5}$ within 12 years. These levels were introduced as they were considered necessary to avoid a lasting impact on soil and food quality. However, the validity of this assumption is still debated, i.e. the necessity to set the initial limit at a level of $60 \mathrm{mg} \mathrm{Cd} / \mathrm{kg} \mathrm{P}_{2} \mathrm{O}_{5}$ and ultimately to reach a level of $20 \mathrm{mg} \mathrm{Cd} / \mathrm{kg} \mathrm{P}_{2} \mathrm{O}_{5}$ to avoid adverse impacts or obtain a balance between inputs and outputs.

Clearly, reducing health risks is a key issue. In 2010, the World Health Organisation (WHO) and Food and Agriculture Organization of the UN (FAO) jointly concluded that: "exposure to Cadmium through the diet for all age groups, including consumers with high exposure and subgroups with special dietary habits, is below the Provisional Tolerable Monthly Intake" (equivalent to $5.8 \mu \mathrm{g} \mathrm{Cd} / \mathrm{kg}$ body weight per week). However, the European Food and Safety Authority (EFSA) set the recommended tolerable level for $\mathrm{Cd}$ in the diet in the EU at a more conservative level of $2.5 \mu \mathrm{g} \mathrm{Cd} / \mathrm{kg} \mathrm{b.w.} \mathrm{per} \mathrm{week} \mathrm{in} 2009$ (confirmed in 2012). The EFSA (2012) found that the weighted average middle bound exposure was $2.04 \mu \mathrm{g} / \mathrm{kg}$ b.w. over a lifetime, which is within its limit. However, both the average intake for infants (MB Mean $2.74 \mu \mathrm{g} \mathrm{Cd} / \mathrm{kg} \mathrm{b.w.} \mathrm{per} \mathrm{week)} \mathrm{and} \mathrm{the} 95^{\text {th }}$ percentile for adults (MB $95^{\text {th }}$ percentile of $3.09 \mu \mathrm{g} \mathrm{Cd} / \mathrm{kg}$ b.w. per week) exceeded the TWI. The EFSA therefore concluded that the exposure to $\mathrm{Cd}$ should be reduced.

The reasoning behind setting maximum limits for contaminants in fertiliser is that a reduced load to soil will lead to a reduction of Cd levels in soil and, hence, reduced uptake by food- and fodder crops. Therefore, the relevant question is: To what extent are the Cd concentrations in food products actually influenced by the Cd concentrations in fertilisers through the soil - crop pathway? This is illustrated in Figure 1.1, which lists the main elements that play a role in the process from load to soils to exposure.

The EFSA (2012) has stated that contamination of agricultural soils can occur through the use of fertilisers. It is important to realise that the EFSA risk assessment approach exposure calculations are based on measurements in food products and consumption patterns, and does not provide a relationship with crops, soils or fertilisers. The ultimate effectiveness of regulation of loads to soil, e.g. via regulation of the quality of fertilisers, still remains to be quantified.

In this concise study, we explore what is known and what is unknown about several of the relationships shown in Figure 1.1. 


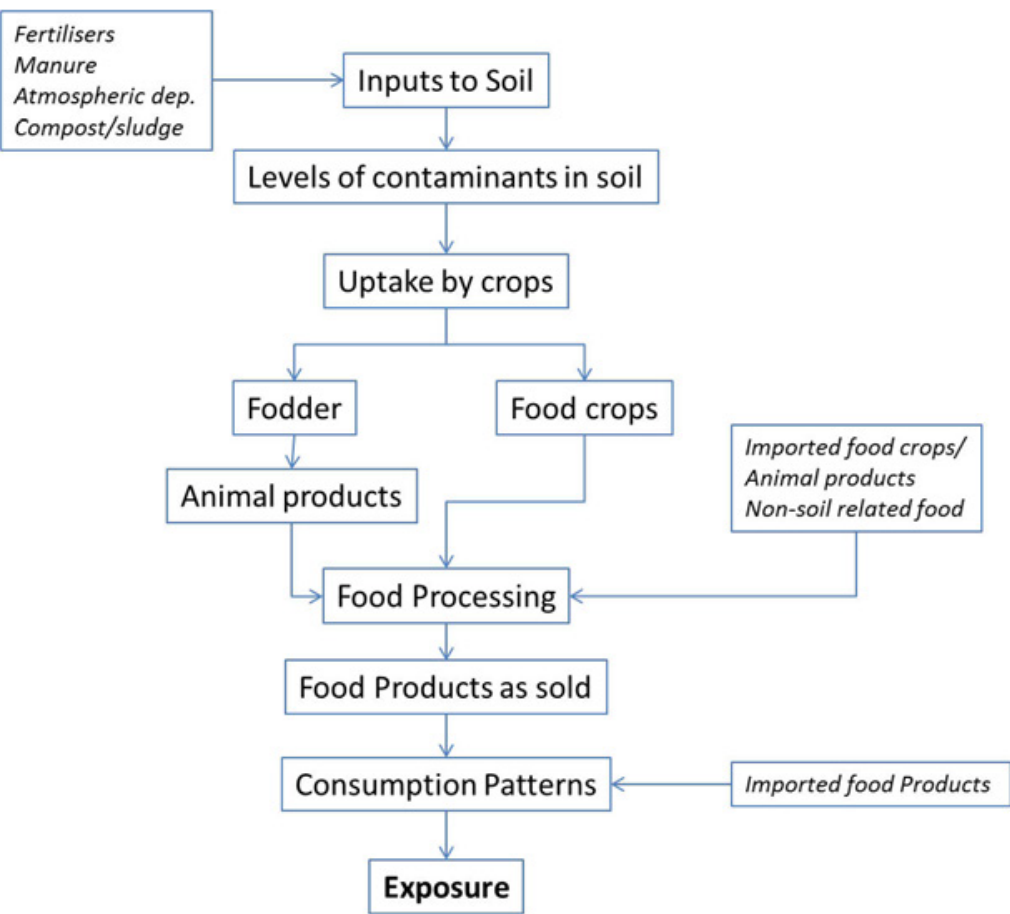

Figure 1.1 Schematic overview of the linkage between fertilisers, soil, crop quality, trade, food processing and exposure (note: other exposure routes besides dietary intake are not considered here).

To achieve this systematically, the following factors are discussed in Chapter 2: input- and output balance of $\mathrm{Cd}$ in soil, $\mathrm{Cd}$ in soil, $\mathrm{Cd}$ in crops, $\mathrm{Cd}$ in food products, and Cd dietary exposure. Cd dietary exposure is chosen as starting point. The kidney is considered to be the most critical target organ for toxicity of $\mathrm{Cd}$ for humans and the toxicological effect depends on the duration and magnitude of exposure. Other toxicological effects are skeletal damage and carcinogenicity (Group 1, EFSA, 2009). $\mathrm{Cd}$ exposure in this review is limited to diets, as food accounts for approximately $90 \%$ of Cd exposure for the non-smoking population (UN, 2010).

In Chapter 3, the information presented in Chapter 2 is used to answer the questions stated in Enclosure 2 of the contract:

1. How relevant/actual are current levels of $\mathrm{Cd}$ in food across EU? Does the regional differentiation in $\mathrm{Cd}$ in soil reflect regional differences in $\mathrm{Cd}$ in food?

2. Is there an explicit link between levels of $\mathrm{Cd}$ in soil and $\mathrm{Cd}$ in food products, and how does this affect human risk assessment?

3. If a link between soil $\mathrm{Cd}$ and levels of $\mathrm{Cd}$ in crops exists, to what extent do different food crops (e.g. potato, wheat, rice) and food groups contribute to human exposure in the EFSA evaluation. And how do other soil factors affect this?

4. Are current, EFSA food groups and levels of Cd aligned with levels predicted by current soil-crop models?

5. What would be the effect of different Cd levels in soil for overall human intake of Cd, taking all food groups considered by the EFSA into account?

Due to the limited nature of this assignment, we made a few clear choices concerning e.g. the crops that we present data on and the approach to some of the modelling of the interaction between fertilisers, soils and crops. We will discuss the nature of these choices and the reasoning behind them in each section of Chapter 2. 


\section{The exposure chain}

\subsection{Exposure of humans to Cadmium}

An important part of the total exposure of humans to Cd occurs through their diets. Relevant nondietary exposure can also occur through smoking (e.g. $0.35 \mu \mathrm{g} \mathrm{Cd} / \mathrm{kg} \mathrm{b.w.} \mathrm{for} \mathrm{an} \mathrm{individual} \mathrm{who}$ smokes 20 cigarettes a week) and exposure to house dust $(0.61 \mu \mathrm{g} \mathrm{Cd} / \mathrm{kg} \mathrm{b.w.} \mathrm{per} \mathrm{week} \mathrm{for} \mathrm{children}$ in contaminated areas) (EFSA, 2009). Such contributions are significant with regard to the total calculated exposure levels, however, the current risk assessment only includes exposure via food. In this report, additional exposure routes are not considered, but it is clear that they can have a significant impact on the total exposure, which may reduce the effectiveness of reducing exposure via food for relevant exposed groups (smokers and children). The two determinants of Cd exposure through food products are: 1). Cd concentrations in the different (groups of) food products; and 2 ). the relative share of each of the food products in the diets of humans. In this section, these two aspects of human exposure to $\mathrm{Cd}$ are addressed.

\subsubsection{Cadmium concentrations in food products}

The EFSA (EFSA, 2009) reported that they obtained 140,000 data for the levels of Cd in various food commodities obtained over the period from 2003-2007, from 20 EU Member States. The sources of the data were mostly four countries: France (ca 18,000 samples - 13\% of data), Germany (ca 43,000 samples $-32 \%$ of data), Romania (ca 12,000 samples - $9 \%$ of data) and Slovakia (ca 40,000 samples - $29 \%$ of data). To obtain a more comprehensive overview of data on Cd in food products across the EU, a country-specific overview of Cd levels in the specific food categories considered was obtained from the EFSA to represent the crop-derived food products, including: subcategory 01B1. Bran and germ, 01B3. Wheat grains and flour, 01B4 Rice, 04B1 Leafy vegetables, 04B7 Spinach, 04B8 Legumes, 051. Potatoes and 06. Fruits. However, the data however could not be delivered in time for inclusion in the current version of the report (delivery in approximately the third week of October 2016, EFSA, pers. comm.).

The database was further extended to contain 174,541 entries, and presented in a later EFSA opinion (EFSA, 2012). Still, the majority of data came from the same four countries, France (ca.

20,000 samples), Germany (ca. 45,000 samples), Romania (ca. 11,000 samples) and Slovakia (ca. 62,000 samples). The food categories used in this later opinion were updated and differed from those in the 2009 opinion, but still, food categories related to crop-derived food products were present, including for example grains for humans, brassica vegetables, leafy vegetables, legume vegetables, potatoes and potato products and pome fruits.

Although there is concern about the current levels of $\mathrm{Cd}$ in food in specific food groups, approximately half of the foods tested contained levels of $\mathrm{Cd}$ at, or below, the detection or quantification limits (EFSA, 2012). In particular, tap water $(0.21 \mu \mathrm{g} / \mathrm{kg})$ and bottled water $(0.42 \mu \mathrm{g} / \mathrm{kg})$ had mean Cd levels that were amongst the lowest of all foods and drinks tested ${ }^{1}$. High values were recorded for algal formulations, seaweeds destined for use as vegetables, oilseeds, horse meat and wild mushrooms, edible offal and aquatic molluscs. However, as stated earlier, it is often not the food with the highest $\mathrm{Cd}$ levels that have the greatest impact on Cd dietary exposure, but foods that are consumed in larger quantities. Table 2.1 shows Cd levels from the EFSA report for food groups that were interesting for this study.

\footnotetext{
1 These values as reported by EFSA. Lower values for the median Cd level in bottled water have been reported by Reimann and Birke (eds.) (2010) with a median value for Cd of van $0.003 \mu \mathrm{g} / \mathrm{l}$ and a 95 percentile of $0.037 \mu \mathrm{g} / \mathrm{l}$.
} 
Table 2.1 Statistical description of Cd occurrence values for selected food categories, focused on the categories that enable comparison to the soil-based predicted crop levels. Values are in $\mathrm{mg} / \mathrm{kg}$ and were obtained from Tables 5, 8 and 9 in the EFSA opinion (EFSA, 2009).

\begin{tabular}{lllllll} 
Food Category & N & P5 & median & Mean (SD) & Max \\
01B1. Bran and germ & 348 & 0.013 & 0.0615 & $0.0647(0.0347)$ & 0.2200 \\
\hline 04B1. Leafy vegetables & 2389 & 0.0005 & 0.0150 & $0.0231(0.0294)$ & 0.1300 & 0.0730 \\
\hline 04B7. Spinach & 867 & 0.0005 & 0.0500 & $0.0615(0.0612)$ & 0.2000 \\
\hline 03B4 Stem and root vegetables & 2452 & 0.0005 & 0.0100 & $0.0205(0.0319)$ & 0.1860 & 0.3245 \\
\hline 051 Potatoes & 2116 & 0.0005 & 0.0150 & $0.021(0.0218)$ & 0.0740 & 0.3000 \\
\hline
\end{tabular}

Although the data for the EFSA study (EFSA, 2012) predominantly originate from a few countries, the study does not give an analysis of the differences between the countries, and the effect that this can have on calculated $\mathrm{Cd}$ exposure. Other studies of $\mathrm{Cd}$ in selected crops or animal feed suggest regional differences within countries and between countries (Ferrari et al., 2013). Figure 2.1 shows some results from this study. From the box plots that show the mean Cd exposure of humans for a selection of EU countries, it is obvious that there are some clear differences in exposure levels between countries. As we shall see in Section 2.3, there are also important regional differences in Cd concentrations between the soils within Europe. Whether or not the exposure differences are related to the differences between soil concentrations is very hard to determine for many reasons. To mention just three: firstly, the exposure data from different studies are often derived from analyses performed using different methods and in different laboratories. This could very easily cause systematic differences between countries. Secondly, for many staple crops, such as cereals, a global market exists, in which large quantities of these food commodities become mixed in the trading process, which mostly eliminates regional differences in Cd concentrations of the raw food crops. And thirdly, human exposure is not only determined by $\mathrm{Cd}$ concentrations in food crops, but also largely by the amount of the different food groups that make up the diet. And diets can vary a lot between (and even within) countries. This topic will be further discussed in the next section.

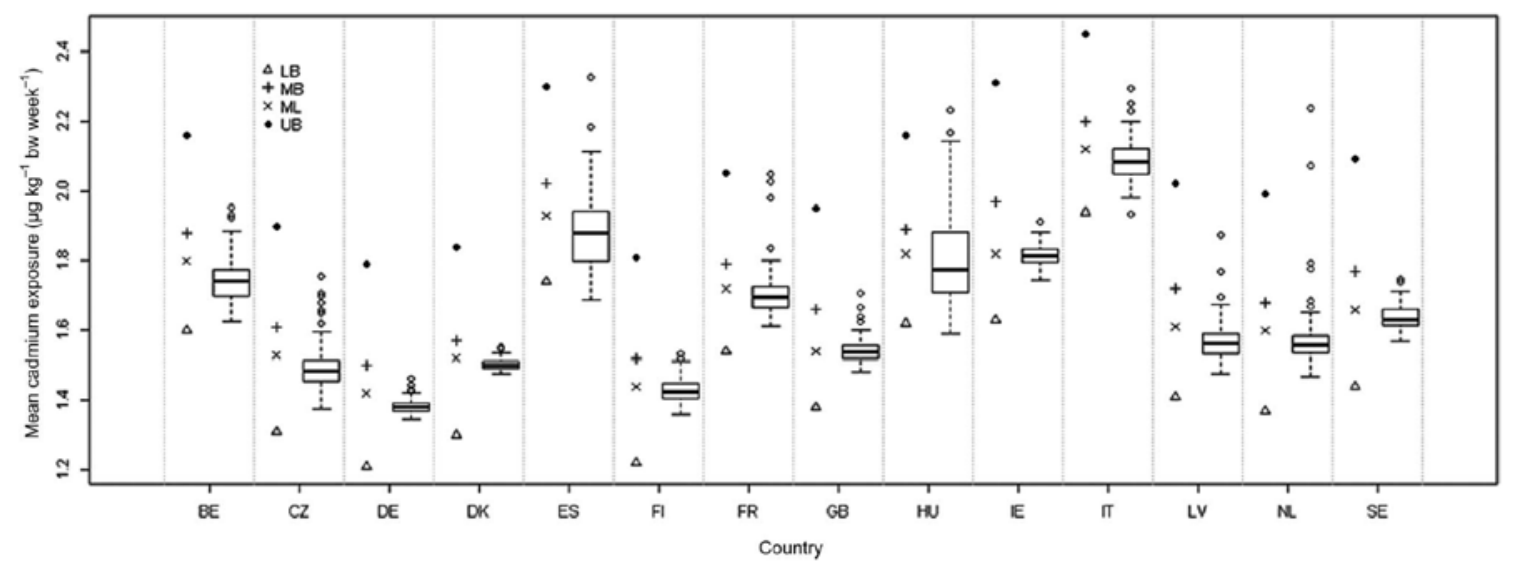

Figure 2.1 Box plots showing the mean Cd exposure of humans for a selection of EU countries (Source: (Ferrari et al., 2013)).

\subsubsection{Food consumption data and exposure to Cadmium}

In 1988, the Joint FAO/WHO Expert Committee on Food Additives (JECFA) set a Provisional Tolerable Weekly Intake (PTWI) of $7 \mu \mathrm{g} / \mathrm{kg}$ body weight (b.w.) for Cd. This was confirmed in 2003. In 2010, the JECFA established a new value that corresponds to a weekly intake of $5.8 \mu \mathrm{g} / \mathrm{kg} \mathrm{b} . \mathrm{w}$.. The EFSA Panel on Contaminants in the Food Chain (EFSA, 2012) has recommended a tolerable weekly intake (TWI) of $2.5 \mu \mathrm{g} / \mathrm{kg}$ body weight to ensure a high-level of protection for all consumers, including exposed- and vulnerable subgroups of the population. 
The food consumption data used by the EFSA $(2009,2012)$ originate from their Comprehensive Database, which is comprised of national-level data. Surveys carried out in various countries differ, as they often study different age groups, and can also differ in methodology. Individuals are categorised into seven age groups (see Figure 2.2). A combination of Cd occurrence values (Cd concentrations in food products) and food consumption data make it possible to make estimates of the dietary exposure to $\mathrm{Cd}$. The EFSA exposure assessments are per country and age group, and are also specified per survey.

According to the EFSA, the food groups that contribute most to dietary Cd exposure are the food groups: 'Cereals and cereal products'; 'Vegetables, nuts and pulses'; and 'Starchy roots and potatoes'. These food groups in particular contributed to the daily exposure, because of their relatively high consumption level (EFSA, 2012). Figure 2.2 shows the relative contributions of all food groups to human $\mathrm{Cd}$ exposure for all age categories, as well as for the total population. The food groups that provide the lowest contribution are eggs, fish, oil and meat.

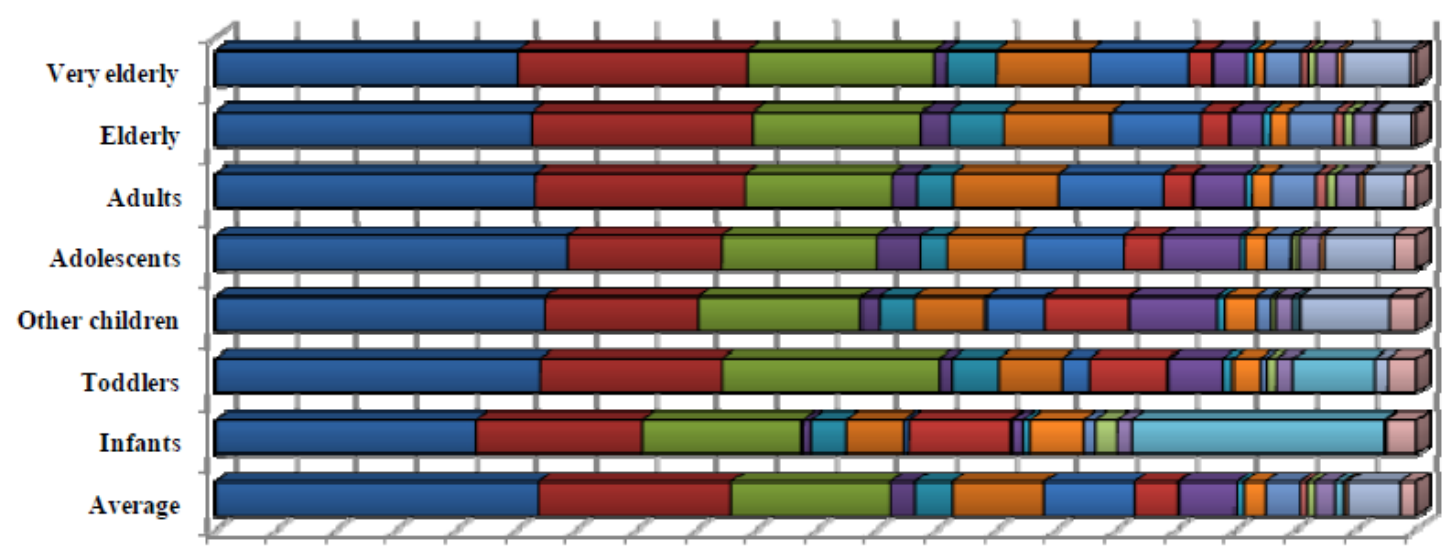

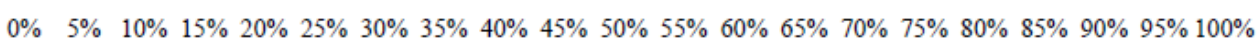
Lower bound relative food category contribution to cadmium exposure

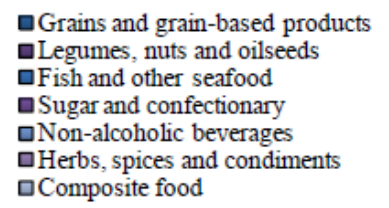

$$
\begin{aligned}
& \text {-Vegetables and vegetable products } \\
& \square \text { Fruit and fruit products } \\
& \square \text { Milk and dairy products } \\
& \square \text { Animal and vegetable fats and oils } \\
& \square \text { Alcoholic beverages } \\
& \square \text { Food for infants and small children } \\
& \square \text { Snacks, desserts, and other foods }
\end{aligned}
$$

$$
\begin{aligned}
& \text { 口Starchy roots and tubers } \\
& \square \text { Meat and edible offal } \\
& \square \text { Eggs and egg products } \\
& \text { 口Fruit and vegetable juices } \\
& \text { 口rinking water } \\
& \square \text { Products for special nutritional use }
\end{aligned}
$$

Figure 2.2 Contributions of 20 broad food categories to lower bound mean Cd exposure per age group and as an average in the total population (EFSA, 2012).

Table 25 of the EFSA (2009) opinion presents an overview of the estimated daily intake of Cd from the different food categories. From this overview, it can be derived that 'Cereals and cereal products' contribute $16.5 \%$, and 'Vegetables, nuts and pulses' $14.5 \%$, whilst 'Starchy roots or potatoes' contribute $10.6 \%$. Food categories that are not primarily included in the soil-based exposure models also contribute to Cd exposure. These include, for example, food categories, such as 'Fish and seafood' (which contribute 6.5\%), 'Meat and meat products, offal' (which contribute 9.8\%), 'Milk and dairy products' (which contribute $4.4 \%$ ).

A later EFSA opinion (EFSA 2012) confirmed these results, and concluded that it is often not the food with the highest $\mathrm{Cd}$ levels that add most to $\mathrm{Cd}$ exposure, but foods that are consumed in larger quantities. Major contributions come from the categories 'Grains and grain-based products' (26.9 \%), 'Vegetables and vegetable products' (16.0\%) and 'Starchy roots and tubers' $(13.2 \%)$, with specific subcategories that include potatoes $(13.2 \%)$, bread and rolls $(11.7 \%)$, fine bakery wares $(5.1 \%)$, chocolate products $(4.3 \%)$, leafy vegetables $(3.9 \%)$ and water molluscs $(3.2 \%)$, contributing the most to Cd dietary exposure. 
The EFSA (2012) concluded that the average dietary Cd exposure of children, and adults at the $95^{\text {th }}$ percentile, exceed the TWI of $2.5 \mu \mathrm{g} / \mathrm{kg} \mathrm{b}$. W. There is a considerable difference in the extent to which the intakes exceed the TWI between adults and children, although the consumption patterns show large similarities (Figure 2.2). A large variation between countries has been observed by the EFSA (2012). For example, the $95^{\text {th }}$ percentile Cd exposure in adults is lowest in Denmark, and highest in Italy $(2.47 \mu \mathrm{g} / \mathrm{kg}$ b.w. per week and $4.81 \mu \mathrm{g} / \mathrm{kg}$ b.w. per week, respectively). This raises the question of: how effective generic measures that include reduced inputs into soil compare to specific measures addressing relevant food products for targeted groups like children? This will be further addressed in Section 2.3.3.

Several other studies have confirmed or refined the picture that has emerged from the EFSA studies. As an example, Schwarz et al. (2014) analysed the data of a large German survey, in which the diets of 20,000 people were surveyed, as well as Cd occurrence data in 545 food products. They showed that cereals and vegetables are the main food crops, through which Cd exposure occurs: together, both food crop categories account for approximately $32 \%$ of the total Cd intake. Table 2.2 shows the details of this. The study of Ferrari et al. (2013) is a refinement of the EFSA study that adds focus to the large amount of left-censored data (results below the limit of detection). This more sophisticated statistical approach confirms the outcomes of the EFSA study.

Table 2.2 Results from the Cd intake calculations based on a large German Food Survey, which show Vegetables and Cereals as the two main food groups that contribute to Cd intake (Schwarz et al., 2014).

\begin{tabular}{|c|c|c|c|}
\hline Main food groups & $\begin{array}{l}\text { Cadmium concentration, } \\
\left.\text { means }(\mu \mathrm{g} \mathrm{kg})^{-1}\right)^{a}\end{array}$ & $\begin{array}{l}\text { Consumption, means } \\
\text { (g food } \mathrm{kg}^{-1} \text { bw week }{ }^{-1} \text { ) }\end{array}$ & $\begin{array}{l}\text { Cadmium intak } \\
\text { (ng kg-1 bw week }{ }^{-1} \text { ) }\end{array}$ \\
\hline Meat & 5.01 & 10.44 & 52.23 \\
\hline Fish & 8.52 & 2.17 & 18.46 \\
\hline Fruits \& Nuts & 2.78 & 44.00 & 122.51 \\
\hline Cereals & 29.18 & 15.93 & 464.89 \\
\hline Eggs & 1.50 & 2.42 & 3.63 \\
\hline Oily Seeds \& Fruits & 20.33 & 2.88 & 58.61 \\
\hline Dairy products & 3.44 & 28.23 & 97.16 \\
\hline
\end{tabular}

Note: ${ }^{\text {a }}$ Based on fresh weight+ consumption-weighted arithmetic means

In addition, studies in various other countries have been performed, such as Sweden (Olsson et al., 2005; Becker et al., 2011; Sand \& Becker, 2012), Belgium (Vromman et al., 2010) and France (Leblanc et al., 2005; Arnich et al., 2012). For Sweden, Olsson found that the food groups that contribute most to dietary Cd intake were: bread; potatoes and roots; vegetables; cereals; and rice. It was also observed, however, that despite increases in Cd concentrations of about 0.05\% per year, which were recorded in Swedish soils, so far, no increase has been detected within food crops (Olsson et al., 2005).

Clearly, an increase in levels of Cd within crops would result in a higher exposure: Olsson et al. (2005), for example, concluded that if Cd levels in food products are equal to the EU maximum permissible levels (EC1881/2006), the dietary intake of $10-25 \%$ of the Swedish population would exceed the previous TWI of $7 \mu \mathrm{g} / \mathrm{kg}$ b.w. per week. And although Cd uptake by crops does eventually increase following rise in soil Cd levels, it remains unclear if the EU maximum permissible levels (EC1881/2006) of Cd in food crops would be reached under current- or future predicted levels in soil. This requires a more in-depth analysis of the whole chain, from load to soil, crop and exposure (as illustrated in Figure 1.1), at regional- and country levels, which, at present, has not yet been carried out. 
Studies by Becker $(2011,2012)$ follow the approach of sampling market baskets purchased in supermarkets in four different Swedish cities by determining the resultant Cd exposure contained within these sample baskets. No difference was found between supermarkets or cities, and Cd exposure was dominated by the inclusion of cereal-based products, potatoes and vegetables in the baskets. In some cases, different dietary patterns can increase the amount of Cd taken up considerably through the inclusion of seafood and spinach in diet(into the range of potatoes), but in general, cereals and potatoes contributed $50 \%$ of the intake, which amounts to about $47 \%$ of the EFSA TWI of $2.5 \mu \mathrm{g} / \mathrm{kg}$ b.w. per week.

For Belgium, Vromman et al. (2010) concisely concluded that: "The population mean, median and $95^{\text {th }}$ percentile of the dietary intake values were 0.98, 0.85 and $2.02 \mu \mathrm{g} \mathrm{Cd} / \mathrm{kg} \mathrm{b.w.} \mathrm{per} \mathrm{week} \mathrm{respectively.}$ Two percent of the Belgian adult population has a dietary Cd intake above the recent TWI of $2.5 \mu \mathrm{g}$ $\mathrm{Cd} / \mathrm{kg}$ b.w. per week. Cereal products and potatoes contribute for more than $60 \%$ to Cd intake." From two total diet surveys carried out in France, Arnich et al. (2012) concluded that Cd exposures increased fourfold in the second survey compared to the first. The reason cannot be a change in diet; the food groups that contribute most to Cd levels (cereals and potatoes) were eaten less and not more. It should, however, be noted that more than half of the Cd measurements in the first survey were below the LOD. Exposure levels in the second survey were $0.16 \mu \mathrm{g} / \mathrm{kg} / \mathrm{day}$ for adults and 0.24 $\mu \mathrm{g} / \mathrm{kg} /$ day for children. These values are in the same range as those for countries like the UK, Canada, USA, Sweden, and Germany. This results in $0.6 \%$ of adults and $14.9 \%$ of the children with an exposure that exceeds TWI of $2.5 \mu \mathrm{g} / \mathrm{kg} /$ week.

Based on all this scientific research, we focused this study on the most important crops for Cd exposure to humans: Cereals, Vegetables and Potatoes.

Ultimately, the effect of Cd consumed by people via food depends, not only on the total amount taken in via food or otherwise, but also on the bioaccessibility and subsequent absorption of Cd from food products. As not all $\mathrm{Cd}$ in food products is equally bioaccessible (i.e. ease of absorption by the body), differences in accessibility will have a pronounced effect on the final internal levels of Cd, which influence health. Dietary $\mathrm{Cd}$ absorption in humans is usually low. Asides from differences in absorption of $\mathrm{Cd}$ between different types of food, low nutritional status and pre-existing health conditions or diseases can lead to higher Cd absorption rates (EFSA, 2009). At present, a range in absorption rates from 1 to $10 \%$ (EFSA, 2009) was used to reflect the impact of such factors on the variation in the absorption of $\mathrm{Cd}$. It is not known to what extent the possible additional variability in the bioaccessibility or regional differences in the chemical availability of $\mathrm{Cd}$ in soil (currently not considered) changes the ranges in dietary exposure.

\subsection{Cadmium: from crop to food product}

For many crops, there is only an indirect relation between Cd content and the Cd exposure/intake by humans, because they are: i). processed into food products; or ii). not sold as fresh- or raw produce. Even for fresh- and raw products, preparation methods can influence the availability and uptake of contaminants by the human body. In this section, we have attempted to assimilate known information about the effect of food processing within the exposure chain on the $\mathrm{Cd}$ intake by humans. We addressed pathways, through which crops are used to feed animals that are consumed by humans, and, thus, may contribute indirectly to Cd exposure in humans (i.e. when $\mathrm{Cd}$ is consumed via products, such as meat and eggs and their products). In addition, we considered the effect of international markets and trade on the Cd content of food commodities, and the effect of specific food processing steps. In this study, we will mostly limit the discussion of these aspects to the main crops that were selected in Section 2.1: Cereals, Vegetables, and Potatoes.

\subsubsection{The effect of international commodity markets and trade}

For various reasons, it is possible that no relation can be found between Cd levels in food and crops grown in Europe. Firstly, the dietary intake of Cd partly stems from consumption of food items that originate from outside Europe, such as rice, tropical fruit and cacao. Chocolate, for example, can 
contain a relatively high content of $\mathrm{Cd}$, but since it does not originate from Europe, there is no relation between the $\mathrm{Cd}$ content in cocoa beans and the quality, and future changes, of EU soils. Secondly, the $\mathrm{Cd}$ content of certain food products (notably seafood) that contributes to $\mathrm{Cd}$ exposure is not related to the quality of soils. Hence, no relation exists between reduced inputs of $\mathrm{Cd}$ via phosphate fertilisers and the dietary intake of Cd from such food products. Thirdly, staple crops are often traded within international markets, in which mixing of different batches is routine. This levels possible differences in grain Cd levels that result from regional differences in soil Cd levels. This mixing can happen at the level of the raw product, as well as in the production process. For example, bread can be made from various types of grain. In this section, we will focus on the relation between diet and Cd exposure from crops grown in the EU.

So far, no study has been found that quantifies the amount of $\mathrm{Cd}$ in European diets that originate from crops grown on soils in EU Member States. The amount of food that is produced in the EU (the selfsufficiency) is high or even close to $100 \%$ for selected food groups, such as cereals, starchy food (for example, potatoes), sugar crops, meat (if the animals are fed with locally grown feedstuff), vegetables, animal fat, eggs and milk. For these food groups, a relation may be expected between $\mathrm{Cd}$ levels in the product and Cd levels in European soils. It should be noted that the use of main food categories masks relevant fractions that are imported, such as rice and sugar cane (EU self-sufficiency levels of $63 \%$ and $83 \%$ respectively). The self-sufficiency is low for tree nuts, oil crops, oil cakes, vegetable oils and fruits. Therefore, only a weak relation is expected for Cd levels in these products and $\mathrm{Cd}$ levels in European soils. No relation is anticipated between Cd levels in fish and seafood and $\mathrm{Cd}$ levels in European soils. In addition, no relation is anticipated for vegetables from glasshouses (tomatoes, cucumber, and peppers), which are predominantly cultured on growing media, such as stone-wool.

In this study, we have, therefore, focused on cereals, vegetables and potatoes, because they contribute most to the $\mathrm{Cd}$ intake of the EU human population. They are also largely produced or grown in Europe. For now, we have considered crops from outside the EU as not highly relevant for the Cd intake, although it must be noted that certain food groups are considered relevant, as specific limit values have been set for these groups (EU, 2006): fungi, cocoa beans and soybeans.

Table 2.3 Agricultural self-sufficiency of the European Union (Noleppa \& Cartsburg, 2013).

\begin{tabular}{cl|c|c|c} 
Main Food Category & $\%$ & Food Category & $\%$ & \multicolumn{2}{c}{ Food category } \\
\hline cereals & 106 & oil crops & 71 & vegetables \\
\hline starchy roots & 106 & oilcakes & 51 & fruits \\
\hline sugar crops & 100 & vegetable oils & 67 & animal fats \\
\hline pulses & 89 & meat & 104 & eggs \\
\hline tree nuts & 36 & fish and seafood & 45 & milk \\
\hline
\end{tabular}

The self-sufficiency estimates make it possible to derive rough estimates of the fraction of each food group that relate to European soils. As far as we know, this has not been quantified in literature. We made an initial attempt to do so, with the results shown in Table 2.4. Although we have focused mainly on cereals, vegetables and potatoes, we made the estimates for all food groups to obtain a good first impression. Two remarks must be made: Firstly, it should be noted that estimating the selfsufficiency of meat is quite complicated (possibly resulting in erroneous estimates in this stage), because a part of the animal feed originates from oil cakes and oil crops from outside Europe. A value for the self-sufficiency of animal feed is required for accurate analysis. On the basis of literature (FEFAC, 2014) ${ }^{2}$ about animal feed $90 \%$ self-sufficiency of animal feed has been assumed here. Secondly, it should be noted that the approach used to estimate self-sufficiency approach here might be too simplistic to quantify the amount of agricultural crops related to European soils. For example,

\footnotetext{
2 Import of animal feeds: $4310^{6}$ tons (dominantly for the production of compound feed, total EU production of compound feeds, including imported feeds, is $15610^{6}$ tons). The total production of animal feeding stuffs (233 $10^{6}$ tons roughages and $24510^{6}$ tons feeds, including farm-grown cereals) is $47810^{6}$ tons (FEFAC, 2014). This results in a self-sufficiency of $91 \%$ (without taking differences between roughage and compound feeds into account).
} 
when the self-sufficiency is $100 \%$, as is the case for potatoes, there can still be an equal amount of import and export between countries of the EU.

Asides from the self-sufficiency at EU level, which has a profound impact on the degree, to which the quality of products can actually be regulated through EU policy, differences between age groups also affect the dietary intake. Dietary Cd exposure varies between age groups. The highest dietary intake levels were estimated for children (middle bound mean $3.96 \mu \mathrm{g} \mathrm{Cd} / \mathrm{kg} \mathrm{b.w.} \mathrm{per} \mathrm{week} \mathrm{for} \mathrm{age} \mathrm{group}$ 'other children'), whilst lower exposures were estimated for adults (middle bound mean $1.7 \mu \mathrm{g} \mathrm{Cd} / \mathrm{kg}$ b.w. per week for age group 'adults')(EFSA, 2012). The middle bound mean exposure for children and the $95^{\text {th }}$ percentile exposure for adults exceed the suggested TWI of $2.5 \mu \mathrm{g} / \mathrm{kg}$ b.w. (EFSA, 2012).

Table 2.4 shows the 20 food groups with the highest contribution to dietary Cd exposure in the groups 'adults' (Table 2.4a) and 'other children' (Table 2.4b) (from Tables 18 and 16 in EFSA, 2012, respectively) in combination with the self-sufficiency data, and a factor with the relation to soil (sea products, and products from soil-less cultures, are not related to soil). The 20 food groups contribute in total approximately $75 \%$ of total exposure of 'adults' and $73 \%$ in 'other children'.

Table 2.4a shows that at least half of the food products are related to EU soils. The contribution to Cd exposure from imported products, sea products and products grown in soil-less cultures is estimated at $21 \%$; hence, the contribution to the exposure from products grown on EU agricultural soils is $55 \%$. Not taken into account is the contribution of smaller food groups that contribute approximately $25 \%$ towards total exposure in adults. In addition, the different $\mathrm{Cd}$ contents in various types of animal feed were not taken into account. If we were to take into account the higher Cd contents of forage, compared to the products used for compound feed, this would probably lead to an increase in the fraction of Cd in human diets from EU soils (EFSA, 2004). Even without considering this, it can be stated that due to the relevant contribution of crops consumed grown on EU soils (at least 55\%), a relation between the intake of $\mathrm{Cd}$ via the diets of Europeans and the quality of agricultural products grown on European soils can be expected.

This analysis suggests that an important part of the Cd exposure comes from soil-related food groups. On the other hand, an almost equal part of the Cd exposure is not soil related.

As the $95^{\text {th }}$ percentile exposure for adults of 3.09 exceeds the suggested TWI of $2.5 \mu \mathrm{g} / \mathrm{kg} \mathrm{b.w.} \mathrm{(EFSA,}$ 2012), the contribution of EU soils of at least 55\%, appears to be relevant. However, the contribution of the different food groups to obtain the $95^{\text {th }}$ percentile is not given in the EFSA (2012) report.

Table 12 in the EFSA 2012 report gives the minimum and maximum contribution of some food groups, which shows that large differences exist within an age group.

What remains unclear, however, is the magnitude of the impact of reduced Cd loads to soil via the proposed reduction of Cd levels in fertiliser on the quality of the relevant food groups identified here. To address this, an assessment of the short- and long term impacts of reduced Cd loads on the Cd content in soil, and subsequently in crops, is needed. 
Table 2.4a Relative contribution of food groups to dietary Cd exposure in adults, and agricultural self-sufficiency of the European Union (based on Table 18 from EFSA 2012, and agricultural selfsufficiency (Noleppa \& Cartsburg, 2013)).

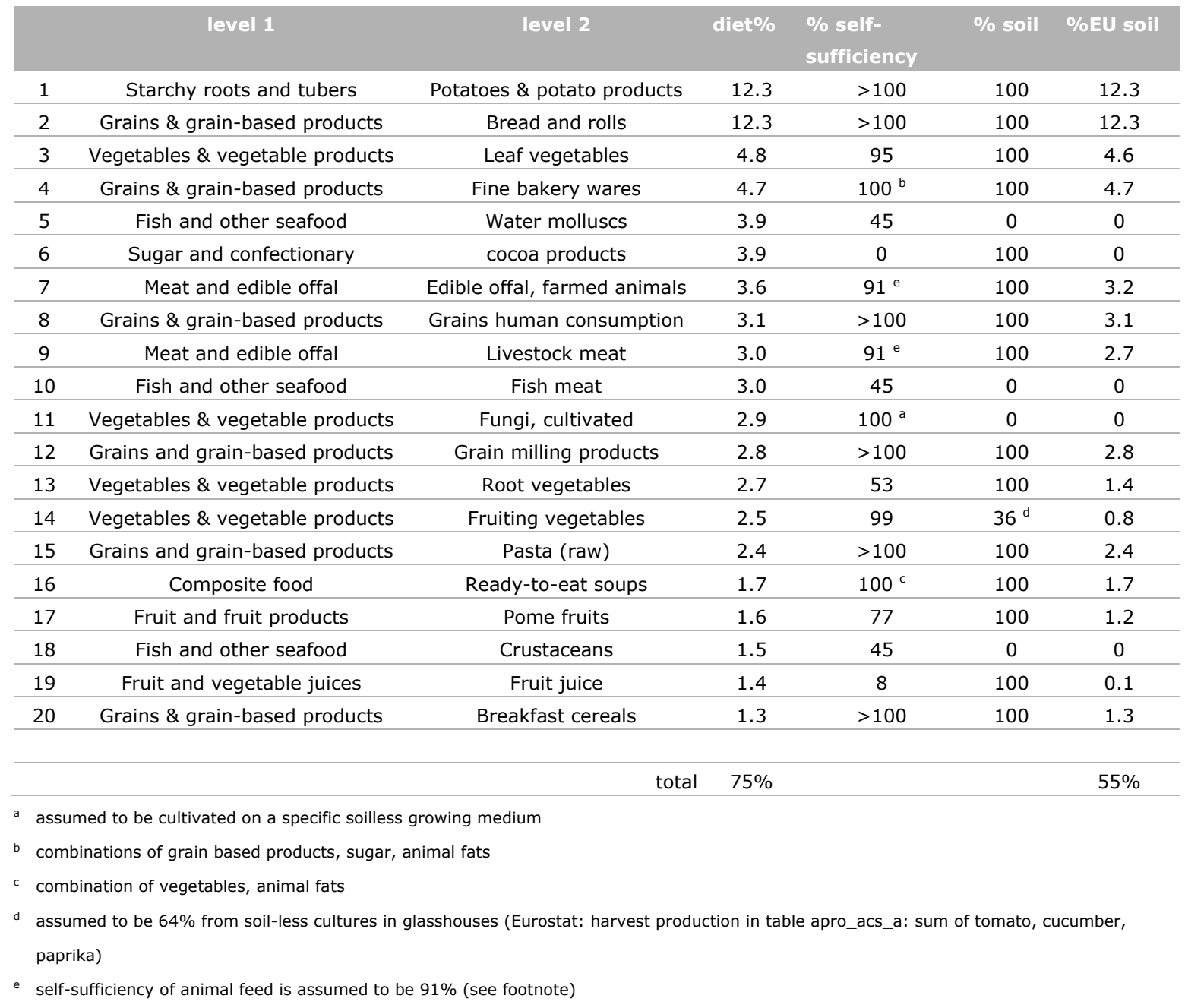

Table 2.4b shows the contribution of EU soils for children, because the weekly middle bound mean cadmium exposure in $\mu \mathrm{g} / \mathrm{kg}$ b.w. for children is 3.96 , and the $95^{\text {th }}$ percentile exposure is 6.58 , and both exceed the suggested TWI of 2.5. For this age group, the contribution of EU soils is calculated to be at least $51 \%$. This implies that even if policies would decrease the contribution of EU soils to zero, a certain percentage of the children still will exceed the suggested TWI. This suggests that a policy aimed at decreasing $\mathrm{Cd}$ exposure for children also requires for measures related to food groups, of which the quality is not related to the quality of EU soils. 
Table 2.4b Relative contribution of food groups to dietary Cd exposure in 'other children', and agricultural self-sufficiency of the European Union (based on Table 18 from EFSA 2012, and agricultural self-sufficiency (Noleppa \& Cartsburg, 2013)).

\begin{tabular}{|c|c|c|c|c|c|c|}
\hline & level 1 & level 2 & diet $\%$ & $\begin{array}{l}\% \text { self- } \\
\text { sufficiency }\end{array}$ & $\%$ soil & $\%$ EU soil \\
\hline 1 & Starchy roots and tubers & Potatoes and potato products & 13.6 & 100 & 100 & 13.6 \\
\hline 2 & Grains and grain-based products & Bread and rolls & 9.9 & 100 & 100 & 9.9 \\
\hline 3 & Sugar and confectionary & Chocolate (cocoa) products & 6.4 & 0 & 100 & \\
\hline 4 & Grains and grain-based products & Fine bakery wares & 6.1 & 91 & 100 & 5.5 \\
\hline 5 & Grains and grain-based products & $\begin{array}{l}\text { Grains for human } \\
\text { consumption }\end{array}$ & 3.3 & 100 & 100 & 3.3 \\
\hline 6 & Grains and grain-based products & Grain milling products & 3.2 & 100 & 100 & 3.2 \\
\hline 7 & $\begin{array}{l}\text { Vegetables and vegetable } \\
\text { products }\end{array}$ & $\begin{array}{l}\text { Cocoa beans and cocoa } \\
\text { products }\end{array}$ & 3.0 & 0 & 100 & \\
\hline 8 & Grains and grain-based products & Pasta (raw) & 2.7 & 100 & 100 & 2.7 \\
\hline 9 & $\begin{array}{l}\text { Vegetables and vegetable } \\
\text { products }\end{array}$ & Root vegetables & 2.7 & 53 & 100 & 1.4 \\
\hline 10 & Composite food & Rice-based meals & 2.3 & 63 & 100 & 1.5 \\
\hline 11 & Milk and dairy products & Milk based beverages & 2.3 & 91 & $0 *$ & \\
\hline 12 & Grains and grain-based products & Breakfast cereals & 2.3 & 100 & 100 & 2.3 \\
\hline 13 & Fruit and vegetable juices & Fruit juice & 2.1 & 8 & 100 & 0.2 \\
\hline 14 & Meat and edible offal & Livestock meat & 2.1 & 91 & 100 & 1.9 \\
\hline 15 & Fish and other seafood & Fish meat & 2.0 & 45 & 0 & \\
\hline 16 & $\begin{array}{l}\text { Vegetables and vegetable } \\
\text { products }\end{array}$ & Fruiting vegetables & 2.0 & 99 & 36 & 0.68 \\
\hline 17 & $\begin{array}{l}\text { Vegetables and vegetable } \\
\text { products }\end{array}$ & Leaf vegetables & 1.9 & 95 & 100 & 1.8 \\
\hline 18 & Meat and edible offal & Edible offal, farmed animals & 1.8 & 91 & 100 & 1.7 \\
\hline 19 & Fish and other seafood & Water molluscs & 1.8 & 45 & 0 & \\
\hline 20 & Composite food & Ready to eat soups & 1.7 & 100 & 100 & 1.7 \\
\hline \multicolumn{3}{|c|}{ Total $\%$ of 20 highest contributing food groups } & $73 \%$ & & & $51 \%$ \\
\hline
\end{tabular}

\subsubsection{Pathways from crops to animal products}

Most of the Cd exposure of humans results from eating crops and crop-based products, and only a minor part results from the consumption of fish, seafood and meat. Therefore, we report only briefly on this pathway, with specific focus on meat and offal, because this pathway has a connection with crops and soils, and as a result, possibly also with $\mathrm{Cd}$ in crops and soils. Many crops are used for animal feed, and as such, $\mathrm{Cd}$ in these crops can be indirectly transferred to the human diet. Some feed crops originate from outside the EU, so they have no relation to EU soils. However, this does not mean that they do not contain Cd, as they are also mostly grown on soils where fertiliser is being used.

Edible offal (kidney and liver) and meat account for 3.6\% and 3.0\% respectively of the Cd exposure from the diet of adults (EFSA, 2012). Cd levels in milk, eggs and muscle (meat) are always much lower than Cd levels in feed, whilst Cd levels in kidney and liver are higher than feed (National Research Council, 2005). Studies have shown relations between Cd content in feed, time of exposure, and Cd in kidney and liver (offal) and less with muscular meat (Vreman et al., 1986; Smith et al., 1991; Stevens, 1991). Transfer coefficients have been derived for kidney and liver (Franz et al., 2008). Cd in muscles often reached a plateau after a certain exposure time (National Research Council, 2005) and, therefore, the transfer coefficients for meat are uncertain. Studies have shown no or weak relations between Cd in feed and Cd in milk (Dowdy et al., 1983; Vreman et al., 1986; Smith et al., 1991; Stevens, 1991; Crout et al., 2004) or eggs (White \& Finley, 1978; Waegeneers et al., 2009). Therefore, transfer coefficients for feed and eggs are not known. 
To better illustrate the approach of feed chain modelling, we reproduced the schematic overview of this approach from van der Fels-Klerx et al. (2011) in Figure 2.3. From this overview, it becomes clear how the relation between $\mathrm{Cd}$ in soils and the impact on human dietary exposure through offal and meat can be modelled. The model takes into account various sources of Cd data (such as soil, compound feed, and water), as well as various transfer models (soil - plant, animal feed meat/organs) and can be used to estimate the effects of various exposure scenarios. The outcomes are Cd levels in kidney and liver that can be compared to maximum levels allowed for these products.

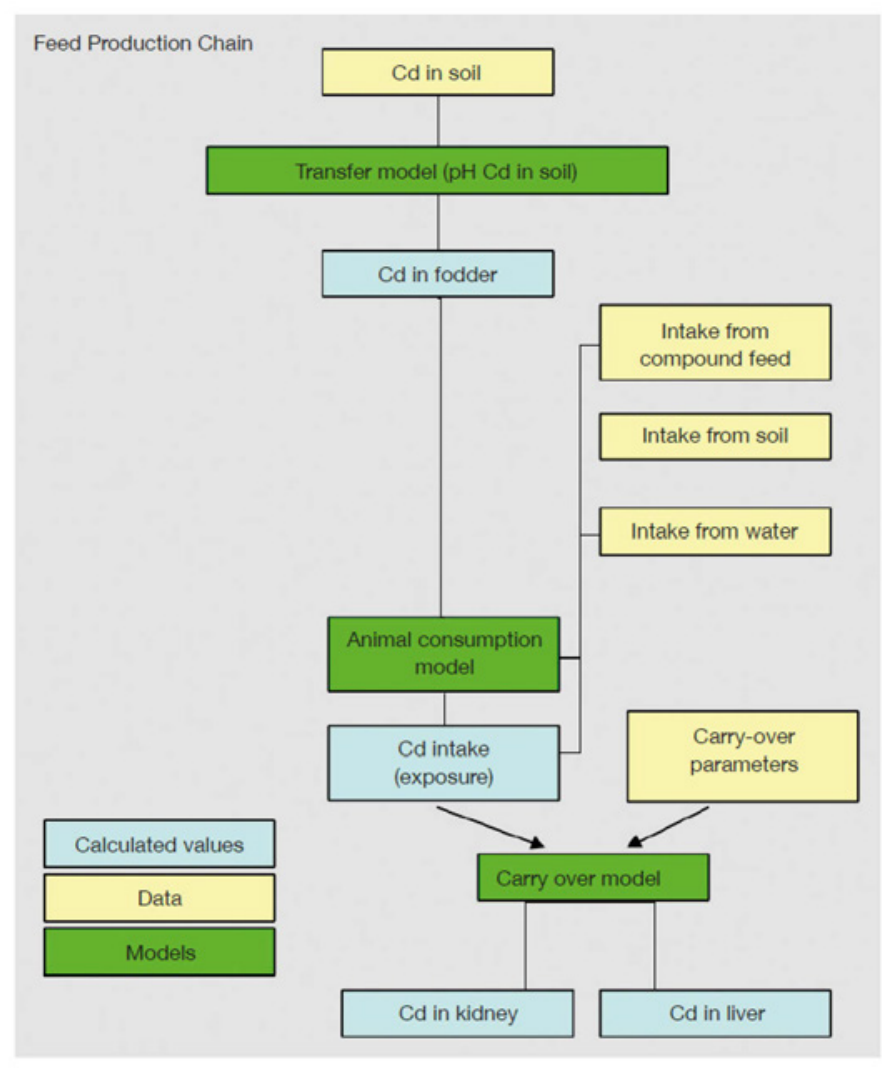

Figure 2.3 Schematic overview of the feed chain modelling by van der Fels-Klerx et al. (2011).

The authors concluded that: 1 ) "only in the most extreme soil scenario (Cd level $2.5 \mathrm{mg} . \mathrm{kg}-1, \mathrm{pH}$ 4.5), Cd exceeded the EC maximum tolerated level in roughage"; 2) assuming linear accumulation, the maximum tolerated levels in one or both organs were exceeded in several scenarios; 3) a steady state model (considering organ excretion of $\mathrm{Cd}$ ) lowered internal Cd levels in organs by approximately one order of magnitude that led to an exceedance in only the kidneys in the most extreme soil scenario; 4) the difference between the two models (linear vs. steady state) is negligible in the animal's first five years of life and that the linear approach is a good descriptor for worst-case situations.

Together, this shows that some aspects of indirect exposure through meat and offal are better known than others, but also that a clear link between Cd levels in soils, on which feed crops are grown and Cd levels in animal organs, such as the kidney and liver, exists. The connection to muscular meat is less clear.

\subsubsection{The effects of food processing}

Another factor is the processing of crops, which can influence the relation between $\mathrm{Cd}$ in crops and $\mathrm{Cd}$ in the diet, for example, in the milling of grains to make flour, or the production of sugar and vegetable oils. We will explore if there is a relation between $\mathrm{Cd}$ in crops and processed foods. 
It has been suggested that by increasing the intensity of grinding of grains to flour can increase the Cd extraction (Jorhem et al., 2001). The mineral content of grains is higher in the outer bran layer. A higher degree of grinding extracts more $\mathrm{Cd}$ from the outer bran and creates a higher ash content. The categories 'bran and germ' and 'wheat grains and flour' in the EFSA report (2009) have higher Cd concentrations (mean 0.06 and $0.03 \mathrm{mg} / \mathrm{kg}$ respectively), as compared to 'wheat products' (mean 0.014 $\mathrm{mg} / \mathrm{kg}$ ). Detailed research has found the highest $\mathrm{Cd}$ concentrations in bran and the pollard fractions and the lowest concentrations in wheat grain and flour (Oliver et al., 1993; Guttieri et al., 2015). However, a relation was found between the $\mathrm{Cd}$ in the different fractions: $\mathrm{Cd}$ concentrations in grains are an effective method to monitor the Cd concentrations in flour and flour products (Oliver et al., 1993).

Many food groups comprise of foods that have been subject to processing, which can influence Cd content. Extraction processes (juicing, oil production by press, milling, cooking) can result in separation of a fraction with high- and low Cd concentrations. Various cooking processes have no influence on Cd content of the majority of foods, although various steaming or baking techniques can decrease Cd in fish (Perello et al., 2008; Domingo, 2011). As crops, sugar beets normally contain similar contents of Cd as wheat grains (Ingwersen \& Streck, 2005), white sugar hardly contains Cd compared to wheat flour (FDA, 2007; FDA, 2016). This shows that $\mathrm{Cd}$ is removed from the food in certain food processes and Cd content in the product bears no relation to the crop and the soil, in which it was produced.

\subsection{Cadmium transfer from soil to crop}

It is clear from the previous sections that there is a relation between Cd levels and EU soils in an estimated $54 \%$ of the food, and the Cd levels in a significant part of the remainder bear a relationship with soils outside Europe, for instance through animal feed. In this section, we will focus further on what is known about the relation between $\mathrm{Cd}$ concentrations in the soil and those in crops.

\subsubsection{Predicting Cadmium levels in crops based on soil Cadmium concentrations}

Soil-crop models are regression models, in which Cd content in crops is explained by various crop and soil factors. In most studies, the $\mathrm{Cd}$ content in soils, clay content, $\mathrm{pH}$ and organic matter content are factors that are taken into account to predict the variation in $\mathrm{Cd}$ in crops. Soil-crop transfer models are well-known, but their applicability is limited to climate, soil-types and crops, for which data have been gathered (McLaughlin et al., 2011; Swartjes, 2011). Validation of the models using independent data is, therefore, an important procedure (Brus et al., 2005; Römkens et al., 2011). From international application of the general model, as shown in Equation 1, it is clear that the general approach has been widely applicable over the last 10 years, from wheat, vegetables and potatoes in Europe to rice in Asia, although specific models must always be derived.

$\log \left(\mathrm{Cd}_{\mathrm{p}}\right)=\mathrm{a}+\mathrm{b} \cdot \mathrm{pH}+\mathrm{c} \cdot \log (\mathrm{OM})+\mathrm{d} \cdot \log ($ clay $)+n \cdot \log \left(\mathrm{Cd}_{\mathrm{s}}\right)$

with:

$\mathrm{Cd}_{\mathrm{p}} \quad$ Cd concentration in crop $(\mathrm{mg} / \mathrm{kg})$

OM organic matter content soil (\%)

Clay clay content soil (\%)

$\mathrm{pH} \quad \mathrm{pH}$ of soil (-)

$\mathrm{Cd}_{\mathrm{s}} \quad$ total $\mathrm{Cd}$ content in soil $(\mathrm{mg} / \mathrm{kg})$

For a number of crops that are relevant for human nutrition, soil-crop transfer functions (Equation 1) have been derived (Römkens et al., 2007; de Vries et al., 2008; Franz et al., 2008): barley, carrot, lettuce, leek, potato, spinach, tomato and wheat. We used these functions, together with data on total metal content in the soil from the GEMAS and FOREGS databases. Soil organic matter content, clay content and $\mathrm{pH}$ were also derived via Kriging using data from other global soil database (de Vries et al., 2014). The whole EU including 27 Member States (EU27) is described in total by 46,650 spatial units (unique combination of soil type, administrative region, slope class and altitude). These were used for estimation of Cd levels in a few crops based on the composition and Cd level of the soils. The aggregated results are shown in Table 2.5. 
Table 2.5 Statistical description of soil-based predicted concentrations of Cd for selected food categories. Values are in $\mathrm{mg} / \mathrm{kg}$ and are based on different $\mathrm{Cd}$ contents, $\mathrm{pH}$, organic matter, and clay in European soils. Calculated Cd concentration were converted from dry- to wet weight using average moisture contents (EPA, 2011).

\begin{tabular}{llll} 
Food Category & P5 & median & 0.063 \\
Wheat grains & 0.030 & 0.021 & 0.140 \\
\hline Lettuce & 0.004 & 0.029 & 0.056 \\
\hline Endive & 0.012 & 0.034 & 0.093 \\
\hline Spinach & 0.013 & 0.009 & 0.120 \\
\hline Potatoes & 0.004 & 0.037 & 0.028 \\
\hline Carrot & 0.021 & 0.003 & 0.019
\end{tabular}

Tables 2.6a and 2.6b show Cd concentrations for a selection of food categories, for which soil-based predicted crop levels can also be calculated. Table 2.6a shows the EFSA information from 2009. Table 2.6b shows updated information from 2012.

Table 2.6a Statistical description of Cd occurrence values for selected food categories, focussing on the categories that enable comparison to the soil-based predicted crop levels. Values are in $\mathrm{mg} / \mathrm{kg}$ and were obtained from Tables 5, 8 and 9 in the EFSA opinion (EFSA, 2009).

\begin{tabular}{lllllll} 
Food Category & N & P5 & median & Mean (SD) & Pax \\
01B3. Wheat grains and flour & 4243 & 0.0005 & 0.0260 & $0.0300(0.0250)$ & 0.1580 \\
\hline 04B1. Leafy vegetables & 2389 & 0.0005 & 0.0150 & $0.0231(0.0294)$ & 0.0800 & 0.0730 \\
\hline 04B7. Spinach & 867 & 0.0005 & 0.0500 & $0.0615(0.0612)$ & 0.2000 \\
\hline 03B4 Stem and root vegetables & 2452 & 0.0005 & 0.0100 & $0.0205(0.0319)$ & 0.1860 & 0.3245 \\
\hline 051 Potatoes & 2116 & 0.0005 & 0.0150 & $0.021(0.0218)$ & 0.0740 & 0.3000 \\
\hline
\end{tabular}

Table 2.6b Description of Cd occurrence values for selected food categories that focus on categories that enable comparison to the soil-based predicted crop levels. Values are presented as the mean lower bound (LB), mean middle bound (MB) and mean upper bound (UB) levels and are expressed in $\mathrm{mg} / \mathrm{kg}$ (from Table 2) (EFSA, 2012).

\begin{tabular}{lllll} 
Food Category & N & Mean LB level & Mean MB level & Mean UB level \\
Grains for humans & 9297 & 0.0325 & 0.0334 & 0.0343 \\
\hline Leaf vegetables & 3414 & 0.0356 & 0.0364 & 0.0371 \\
\hline Legume vegetables & 233 & 0.00289 & 0.00439 & 0.00589 \\
\hline Potatoes and products & 2280 & 0.021 & 0.0217 & 0.0224 \\
\hline
\end{tabular}

Table 2.7 shows an initial comparison of the estimations of Cd levels in crops based on the soil-crop transfer models, and Cd occurrence values as reported by EFSA for related food groups. It is not always evident which comparisons are most sensible. We chose to perform a comparison between leafy vegetables, and lettuce or endive. The predicted mean values for lettuce $(0.021)$ and endive (0.029) are a little higher than the occurrence data for leafy vegetables (0.015). A comparison also seemed possible between 'Stem and root vegetables' and carrot or leek. The predictions for carrot (0.037) and leek (0.003) show a large variation between crops, and are in the range of the occurrence data for 'stem and root vegetables'. Spinach and potatoes are categories in both approaches and for both crops the soil based predictions seem to underestimate the measured EFSA data somewhat. The food group, 'Wheat grains and flour', is, of course, a difficult group, because this contains a large processed component, whereas the soil-based models only predict Cd levels in the entire wheat grain.

Considering the quick and general approach that we took to make these estimations, combining different soil datasets and comparing unrelated crop measurements with the predictions that we 
made, the soil based predictions can be considered rather good, as reflected by the deviation between data and predictions, which is less than a factor of 2 . This illustrates that exposure values based on soil-based models could be used to model part of the exposure. To further estimate the consequences of Cd soil levels for overall exposure values requires further analysis of to what extent Cd soil levels and subsequent accumulation in crops will result in transfer of the $\mathrm{Cd}$ to other food categories.

Table 2.7 Comparison between soil-based predicted Cd concentrations and EFSA data for selected food categories ${ }^{3}$.

\begin{tabular}{|c|c|c|c|c|c|c|c|}
\hline \multirow[t]{2}{*}{ Food Category } & \multicolumn{3}{|c|}{ EFSA2009 } & \multirow[t]{2}{*}{ Food Category } & \multicolumn{3}{|c|}{ Soil-based predicted } \\
\hline & P5 & P50 & P95 & & P5 & P50 & P95 \\
\hline Wheat grains and flour & 0.005 & 0.0260 & 0.08 & Wheat grains & 0.03 & 0.063 & 0.14 \\
\hline Leafy vegetables & 0.005 & 0.0150 & 0.073 & Endive & 0.012 & 0.029 & 0.093 \\
\hline Spinach & 0.005 & 0.0500 & 0.186 & Spinach & 0.013 & 0.034 & 0.12 \\
\hline \multirow[t]{2}{*}{ Stem and root vegetables } & \multirow[t]{2}{*}{0.005} & \multirow[t]{2}{*}{0.0100} & \multirow[t]{2}{*}{0.074} & carrot & 0.021 & 0.037 & 0.079 \\
\hline & & & & leek & 0.0005 & 0.003 & 0.019 \\
\hline
\end{tabular}

\subsubsection{Regional differences in Cadmium levels in soils and crops}

If Cd levels in soil, and its regional- or national variability is an important factor that influences Cd levels in crops, it can be expected that $\mathrm{Cd}$ occurrence in food items differs between countries or regions. The EFSA and Ferrari et al. (2013) calculated Cd in the diet of all EU Member States, on the basis of consumption data and Cd levels in the food groups. The EFSA used average values for all food items and, therefore, differences between countries were calculated only on the basis of different consumption patterns. Relevant differences were calculated between surveys: for example, in Belgium and the Netherlands, the sugar and confectionary category constituted $13 \%$ and $16 \%$ of the diet, respectively, whilst it did not exceed $4 \%$ in the other surveys (EFSA, 2012). In Italy, Spain and France, the contribution of fish and seafood, and specifically, molluscs, was high and ranged from nine to $23 \%$.

This illustrates that as average $\mathrm{Cd}$ levels in food products were used in exposure calculations in combination with differences in diets across the EU, it is hard to relate differences in exposure to differences in soil Cd concentrations alone.

Nevertheless, the contribution of products in the exposure assessment - the quality of which can be related to the $\mathrm{Cd}$ soil content - warrants a more in-depth analysis of the variability of Cd across soils. This will provide more insight into how this variability in soil Cd affects the exposure that results from consumption of such crops. In this section, we will give an impression of the variation in $\mathrm{Cd}$ concentrations in EU soils.

On the basis of the soil map (Figure 2.4)(Lado et al., 2008), high Cd concentrations in soils occur in Ireland, the UK and parts of France, Belgium and Germany (up to $0.6 \mathrm{mg} \mathrm{Cd} / \mathrm{kg}$ soil), whereas low concentrations are expected in Finland, Spain and Portugal $(0.13,0.22,0.07 \mathrm{mg} \mathrm{Cd} / \mathrm{kg}$ soil respectively). To predict $\mathrm{Cd}$ levels in crops, soil information on $\mathrm{pH}$, organic matter and clay is also required. Soil-based predicted Cd concentrations for all EU Member States are given in Annex 1. Average predicted $\mathrm{Cd}$ concentrations in wheat in Ireland and Belgium differ $(0.10$ and $0.12 \mathrm{mg} / \mathrm{kg}$ respectively), with predicted concentrations in Finland, Spain and Portugal $(0.05,0.06,0.05 \mathrm{mg} / \mathrm{kg}$ respectively). It shows that predicted differences in crops are less than differences in soils, because not all $\mathrm{Cd}$ in soil is available to crops. This shows that it will be difficult to show differences between EU Member States.

3 It should be noted that the percentile values of a soil-based Cd concentrations are not similar to the percentile values of the food categories in EFSA. The percentile values of the soil-based Cd concentrations describe the variation as caused by the difference in soil characteristics. Also it should be noted that the soil-crop transfer models are based only Dutch data, and the amount of samples from polluted areas is probably relative high. 


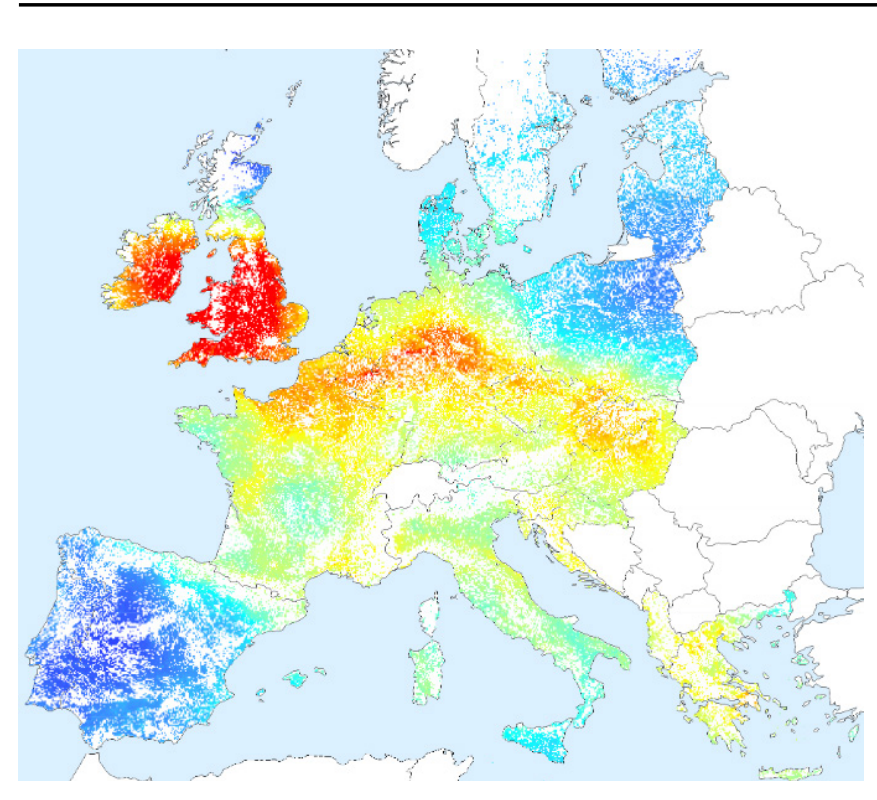

Figure 2.4 Map of total Cd content in European soils, scaling from low (blue: lowest $0.06 \mathrm{mg} / \mathrm{kg}$ ) to high Cd contents (red: highest $0.59 \mathrm{mg} / \mathrm{kg}$ )(Lado et al., 2008).

However, based upon the differences in the soil map, regional differences between Cd concentrations are relevant. Two relevant remarks should be made in conjunction to this map. Firstly it should be noted that total $\mathrm{Cd}$ levels in soils are dominated by geological factors, such as the parent material. Secondly, it should be noted that it is not the total Cd levels that determine the uptake by crops., but rather the bioavailable Cd levels. The bioavailability of $\mathrm{Cd}$, in addition to the total Cd levels, strongly depends on soil factors, such as $\mathrm{pH}$, organic matter content, and clay content. These soil factors also show regional variation in Europe. Therefore, it could well be that the absolute difference in Cd levels in soil, as shown in Figure 2.4, do not match with actual Cd availability to crops. Hence, the impact of reduced loads can be quite different in, for example, comparing crop response in Cd uptake in a calcareous clay soil in the Mediterranean area (where high clay, high pH soil are very common), to that in areas with low pH and sandy soils (e.g. in parts of the Netherlands and Belgium). These differences should be considered in discussion of the usefulness of a generic standard in view of crop safety, both in terms of soil quality and also in terms of acceptable or critical loads to soils.

The effect of all these soil factors is very relevant, and together, they determine the bioavailability and, hence, plant uptake of Cd (de Vries et al., 2007; Franz et al., 2008; Römkens et al., 2011). Calculated critical soil levels in rice fields, levels at which rice exceed limit values, can change a factor of two, by changing the $\mathrm{pH} 1$ unit, by changing the CEC (Cation-Exchange Capacity or clay content) by a factor of four, or by changing the Cd content in soil by a factor of 2.5 (Römkens et al., 2011). For other crops, the factors for clay, $\mathrm{pH}$ and soil organic matter differ. For example, for some $\mathrm{crops} \mathrm{pH}$ hardly has any effect whilst for lettuce and leek, the effect of soil pH is relevant. Effects of organic matter and CEC are rather similar for most crops.

In Table 2.5, the difference between P5 and P95 for the soil-based predicted Cd concentrations are factors of $4,4,8,10,13,39$, respectively, for wheat, carrot, endive, spinach, lettuce and leek. Therefore, regional differences of $\mathrm{Cd}$ levels in crops are anticipated for sensitive crops, such as lettuce and leek, but appear less relevant for wheat and carrot.

Experimental tests with different wheat varieties at different soils, with different Cd contents in the soil have demonstrated that similar differences are found between cultivars at various locations. It has also been demonstrated that site effects dominated over the cultivar effects in practice in Australia (Oliver et al., 1995).

Effects of Cd containing P-fertilisers on Cd in soils and Cd in crops have been demonstrated clearly in long-term studies (Abraham et al., 2016). In regional studies, often in wheat, the Cd content in soils and crops has been studied (Chaudri et al., 1995). Regional differences have been found in Australia 
(Oliver et al., 1993) that resulted in a factor 2 difference between two areas. Cd contents in grains are lower in Australia than the USA, which suggest variations in soil type, wheat varieties, or other factors (Oliver et al., 1993). Alongside this, Cd in soil and soil characteristics, varieties between crops are also relevant, as was shown for rice (Römkens et al., 2011), maize (Kurz, 1999), wheat (Adams et al., 2004) (Kubo et al., 2008), lettuce, celery (Zhang et al., 2013a; Zhang et al., 2013b), carrot, pea, onion, and spinach (Alexander et al., 2006): differences between the lowest and the variety with the highest amount to a factor 3 to 10 . Current soil-based Cd predictions in crops do not take crop varieties into account. In most countries, the varieties differ, which makes comparisons between countries less straightforward. It is also well-known that in non-polluted soils with a low pH (Great Plains of USA), some wheat genotypes (hard winter-wheat) can accumulate Cd in grains and exceed the European limit value (Guttieri et al., 2015).

\subsubsection{Predicting effect of lowering EU soil Cadmium concentrations on Cadmium exposure}

As soil-based predicted cadmium concentrations give reasonable predictions of the current Cd content in crop products, it is possible to also use the model to predict the effect of soil Cd concentrations on $\mathrm{Cd}$ in crops. By using estimates for the self-sufficiency and the dependency on soil (Table 2.4), it is possible to predict the decrease on Cd exposure due to lower Cd concentrations in EU soils.

For all spatial units (unique combination of soil type, administrative region, slope class and altitude), the effect of a lower soil Cd content was calculated. It is assumed that in all units, the Cd content is decreased by the same factor. The surface weighted average Cd content per crop was calculated for ten crops. Decreasing the soil Cd content by a factor of 2 resulted in Cd contents in crop products that are a factor of 1.4-1.8 lower, except for leek, for which the predicted effect is larger (Annex 2). This calculation is only possible for the ten crops in Table 2.7, for which soil-plant relations are available. This results in a relative decrease of the Cd content in crops.

These calculations were used to predict the effect of lower soil Cd contents on the EFSA food groups. For example, if the calculated effect of decreasing the soil Cd content by a factor of two, results in a relative effect of a factor of 1.7 for spinach, this relative effect was used to predict the effect of the lower soil Cd content for the EFSA food group 'leafy vegetables'. The assignment of the calculated values from Annex 2 for the EFSA food groups is given in Table 2.8.

Table 2.8a shows that the dietary exposure for adults from the 20 highest contributing food groups is $1.28 \mu \mathrm{g} / \mathrm{kg}$ b.w. per week. The total dietary exposure is on average $1.70 \mu \mathrm{g} / \mathrm{kg} \mathrm{b.w.} \mathrm{per} \mathrm{week} \mathrm{for}$ adults. The contribution of EU soil related food is at least $0.93 \mu \mathrm{g} / \mathrm{kg} \mathrm{b.w.} \mathrm{per} \mathrm{week.} \mathrm{If} \mathrm{the} \mathrm{soil} \mathrm{Cd}$ content is decreased by a factor of 2, the contribution of EU soil-related food will decrease to $0.60 \mu \mathrm{g} / \mathrm{kg}$ b.w. per week. The total average dietary exposure for adults could decrease from 1.70 to $1.37 \mu \mathrm{g} / \mathrm{kg}$ b.w. per week.

As the $95^{\text {th }}$ percentile exposure for adults of 3.09 exceeds the suggested TWI of $2.5 \mu \mathrm{g} / \mathrm{kg} \mathrm{b.w.} \mathrm{(EFSA,}$ 2012) it would be relevant to calculate the effect of decreasing the soil Cd content on this group. However, as mentioned earlier, the contribution of the different food groups to obtain the $95^{\text {th }}$ percentile is not given in the EFSA (2012) report. 
Table 2.8a Contribution of 20 food groups ( $\mu \mathrm{g} \mathrm{Cd/b.w.} \mathrm{per} \mathrm{week)} \mathrm{with} \mathrm{the} \mathrm{largest} \mathrm{contribution} \mathrm{to} \mathrm{Cd}$ exposure for the age group adults, and the effect of decreasing the Cd content in EU soils by a factor of 2 .

\begin{tabular}{|c|c|c|c|c|c|c|c|}
\hline & \multirow[t]{2}{*}{ level 1} & \multirow[t]{2}{*}{ level 2} & \multicolumn{3}{|c|}{$\begin{array}{l}\text { Cd exposure } \\
\text { ( } \mu \mathrm{g} / \mathrm{kg} \text { b.w. per week) }\end{array}$} & \multicolumn{2}{|c|}{$\begin{array}{l}\text { Factor based on } \\
\text { Annex } 2\end{array}$} \\
\hline & & & total & EU soil & $0.5 \mathrm{Cd}$ EU soil & & \\
\hline 1 & Starchy roots and tubers & Potatoes \& potato products & 0.21 & 0.21 & 0.12 & 0.57 & potato \\
\hline 2 & Grains \& grain-based products & Bread and rolls & 0.21 & 0.21 & 0.14 & 0.65 & wheat \\
\hline 3 & Vegetables \& vegetable products & Leaf vegetables & 0.08 & 0.08 & 0.05 & 0.59 & spinach \\
\hline 4 & Grains \& grain-based products & Fine bakery wares & 0.08 & 0.08 & 0.05 & 0.65 & wheat \\
\hline 5 & Fish and other seafood & Water molluscs & 0.07 & 0.00 & & & \\
\hline 6 & Sugar and confectionary & cocoa products & 0.07 & 0.00 & & & \\
\hline 7 & Meat and edible offal & $\begin{array}{c}\text { Edible offal, farmed } \\
\text { animals }\end{array}$ & 0.06 & 0.05 & 0.04 & 0.65 & wheat \\
\hline 8 & Grains \& grain-based products & Grains human consumption & 0.05 & 0.05 & 0.03 & 0.65 & wheat \\
\hline 9 & Meat and edible offal & Livestock meat & 0.05 & 0.05 & 0.03 & 0.65 & wheat \\
\hline 10 & Fish and other seafood & Fish meat & 0.05 & 0.00 & & & \\
\hline 11 & $\begin{array}{c}\text { Vegetables \& vegetable } \\
\text { products }\end{array}$ & Fungi, cultivated & 0.05 & 0.00 & & & \\
\hline 12 & $\begin{array}{c}\text { Grains and grain-based } \\
\text { products }\end{array}$ & Grain milling products & 0.05 & 0.05 & 0.03 & 0.65 & wheat \\
\hline 13 & $\begin{array}{c}\text { Vegetables } \& \text { vegetable } \\
\text { products }\end{array}$ & Root vegetables & 0.05 & 0.02 & 0.02 & 0.82 & carrot \\
\hline 14 & $\begin{array}{c}\text { Vegetables \& vegetable } \\
\text { products }\end{array}$ & Fruiting vegetables & 0.04 & 0.01 & 0.01 & 0.82 & tomato \\
\hline 15 & $\begin{array}{c}\text { Grains and grain-based } \\
\text { products }\end{array}$ & Pasta (raw) & 0.04 & 0.04 & 0.03 & 0.65 & wheat \\
\hline 16 & Composite food & Ready-to-eat soups & 0.03 & 0.03 & 0.02 & 0.82 & tomato \\
\hline 17 & Fruit and fruit products & Pome fruits & 0.03 & 0.02 & 0.02 & 0.82 & tomato \\
\hline 18 & Fish and other seafood & Crustaceans & 0.03 & 0.00 & & & \\
\hline 19 & Fruit and vegetable juices & Fruit juice & 0.02 & 0.00 & 0.00 & 0.82 & tomato \\
\hline 20 & Grains \& grain-based products & Breakfast cereals & 0.02 & 0.02 & 0.01 & 0.65 & wheat \\
\hline & Total of 20 highe & est contributing food groups & 1.28 & 0.93 & 0.60 & & \\
\hline & Total average dietary exp & posure of age group "adults" & 1.70 & & & & \\
\hline
\end{tabular}

Table 2.8b shows the calculated results for the age group 'other children'. The total dietary exposure is on average $3.96 \mu \mathrm{g} / \mathrm{kg}$ b.w. per week for children. The contribution of EU soil related food is at least $2.03 \mu \mathrm{g} / \mathrm{kg}$ b.w. per week. If the soil Cd content is decreased by a factor of 2 , the contribution of EU soil related food will decrease to $1.30 \mu \mathrm{g} / \mathrm{kg} \mathrm{b.w.} \mathrm{per} \mathrm{week.} \mathrm{The} \mathrm{total} \mathrm{average} \mathrm{dietary} \mathrm{exposure} \mathrm{for}$ children of 3.96 could become $3.26 \mu \mathrm{g} / \mathrm{kg}$ b.w. per week, which is still above the suggested TWI of $2.5 \mu \mathrm{g} / \mathrm{kg}$ b.w. per week. These rough calculations show that a $50 \%$ decrease of the soil Cd content alone is not enough to reach the TWI for children. 
Table 2.8b Contribution of 20 food groups with the largest contribution to Cd exposure for the age group 'other children', and the effect of decreasing the Cd content in EU soils with a factor of 2.

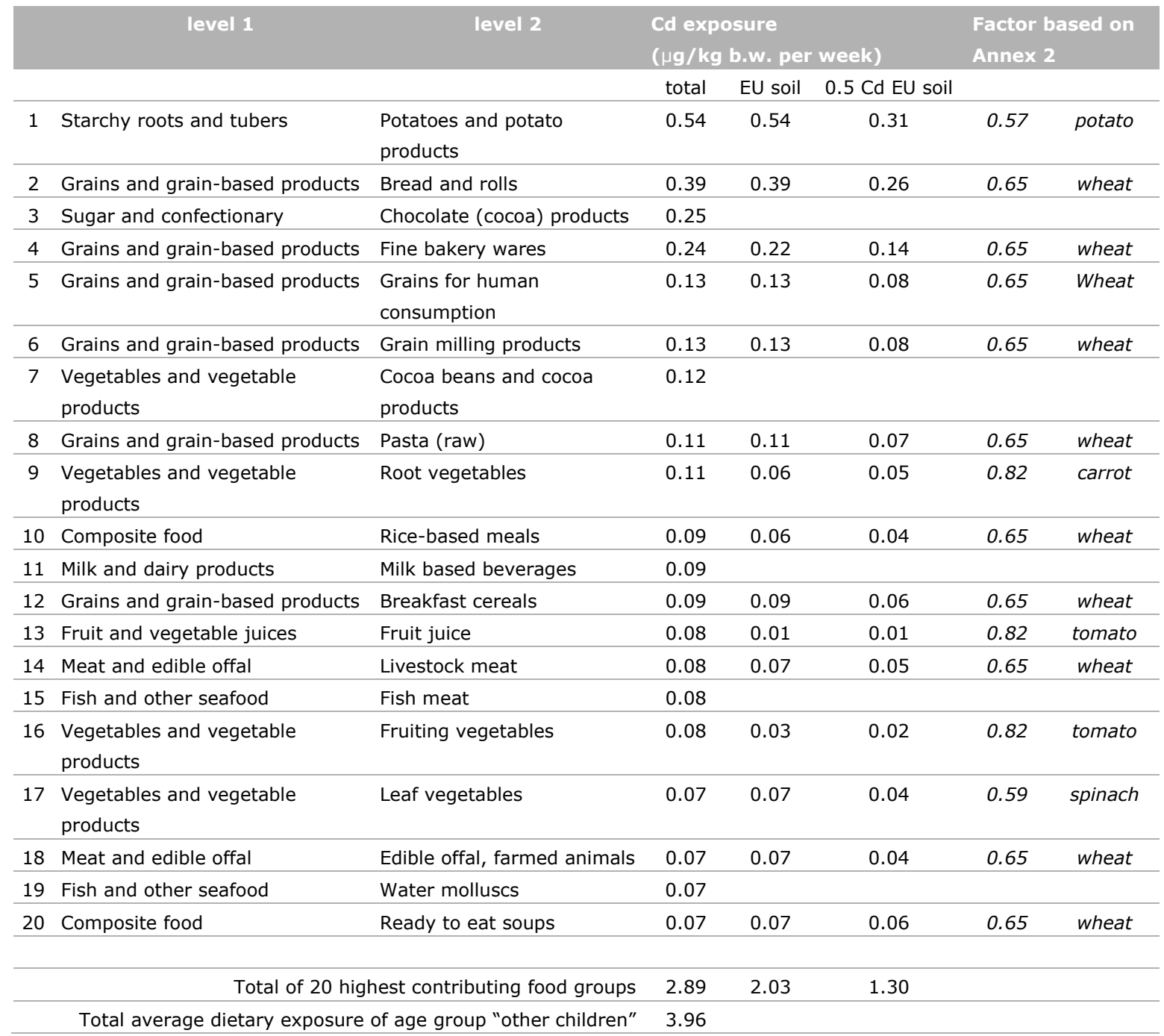

Some notes should be made about the assumptions made for the calculations:

- Using a scenario to decrease the Cd inputs, and use a modelled output through leaching, might offer a spatially differentiated decrease of the Cd content in EU soils.

- In reality, lower $\mathrm{Cd}$ concentrations in soils can be reached by leaching of $\mathrm{Cd}$ to lower soil layers and decreasing the inputs. Currently $\mathrm{Cd}$ in EU soils is found in different soils layers but predominantly in the upper soil layers. A decrease in the upper layers will then result in an increase of Cd in the lower layers. The effects on crops will vary, because most vegetables have a root system that is not deep, whilst cereals have roots that grow much deeper.

- The effect of lowering Cd contents in soil by leaching, and its effects on crops, are not well-known (Koopmans et al., 2008).

\subsection{Sources of Cadmium in soil}

One of the underlying assumptions to revise the fertiliser composition in terms of the maximum allowed $\mathrm{Cd}$ content is the hypothesis that by reducing inputs to soils, the quality of crops (i.e. Cd content) can also be reduced, thus, resulting in lower exposure of human beings to Cd via intake of food and food products. It has already been discussed in previous sections that such a one: one relation between soil quality and exposure can be difficult to obtain due to poor relations between soil and crop quality, processing of raw products, consumption of products the quality whereof is not related to soil (e.g. seafood) and trade/import of relevant food groups, amongst other factors. Nevertheless, it was also concluded that for a number of important food groups, notably those based 
on wheat, potato and vegetables, the relation between soil and crop quality is quite strong. As such, differences in existing soil quality can already result in different exposure levels. Clearly future changes in the soil content would also affect exposure levels. Changes in soil quality (here: Cd content) are largely related to the balance between inputs (fertiliser, manure, air, compost or sludge, to mention the most relevant) and outputs (crop uptake and leaching). Clearly, cropping patterns, as well as leaching losses can vary as well due to changes in rainfall and temperature, amongst other factors, but at the moment, such changes are not considered. Hence, predicted changes in soil quality are largely related to changes in inputs. In this context, the proposed levels of maximum tolerable Cd levels in inorganic fertilisers can result in significant changes in inputs to arable soils. This then raises the question of: to what extent this variation in the load of $\mathrm{Cd}$ to arable soil will affect the Cd content in soils and, from there, the Cd content in crops?

In a recent modelling study, the trend of $\mathrm{Cd}$ accumulation in selected arable soils across the EU has been quantified (Smolders \& Six, 2013; Six \& Smolders, 2014). These studies serve as an update of the opinion of the European Commission's (EC's) Scientific Committee on Toxicity, Ecotoxicity and the Environment (CSTEE, 2002). These studies are an assessment of the effect of using mineral phosphate fertilisers on $\mathrm{Cd}$ accumulation in soils. The studies calculate the balance between the input and output of $\mathrm{Cd}$ in European arable soils, and they calculate scenarios of long-term change of Cd in soils. The studies (Smolders \& Six, 2013; Six \& Smolders, 2014) have been reviewed by the EC's Scientific Committee on Health and Environmental Risks (SCHER, 2015). SCHER accepted the new information, but did not accept some assumptions, as these were based on insufficient scientific information. In addition, SCHER prefers another choice for the worst-case scenario: for Cd in deposition, in manure, soil pH and the organic carbon content in European soils, and also a higher fertiliser input in the worst-case scenario. Those aspects will not be repeated here. Two other critical aspects are discussed and suggestions to improve the calculations are given:

- the validity of mass balance-approach for EU arable soils; and

- the validity of the dynamic modelling of Cd in EU soils.

The central assumption of Smolders and Six (2013) is that a mass balance of Cd in European arable soils is appropriate, and that it is not necessary to calculate mass balances for different cropping systems, soils types, countries, climate or other units. However, Smolders and Six (2013) have not checked if this assumption is correct. Here, we evaluate four arguments as to why a detailed or a simple mass balance for Europe is appropriate in view of a change in the Cd soil content and, ultimately, the relation with exposure of human beings to $\mathrm{Cd}$ :

- A simple mass balance for Europe can be a good average if many relations are near to linear.

- The effect of using mineral phosphate fertilisers on Cd accumulation in soils.

- The input of Cd to soils is of major importance to calculate an appropriate Cd mass balance.

- Contribution and distribution of other soil amendments.

A full analysis of the main discussion items of the approach by Smolders and Six (2013) is beyond the scope of this report, but the issues listed above are discussed in more detail in Annex 3 . It is important to realise though that an update of this approach by Smolders and Six (2013) is upcoming, which may include some of the issues raised here. Therefore, we will not further discuss the possible differences between the results of both studies here. 
Another aspect that will affect the impact of fertiliser regulations is related to the relevance of $\mathrm{Cd}$ inputs to soil across the EU. As shown by the wide range in Table 2.9 (Cd inputs from fertiliser range from almost 0 to $2 \mathrm{~g} / \mathrm{ha} / \mathrm{yr}$ ), differences in application rates and quality across different countries lead to a substantially different contribution of $\mathrm{Cd}$ in fertiliser across the EU, as is shown in Figure 2.5.

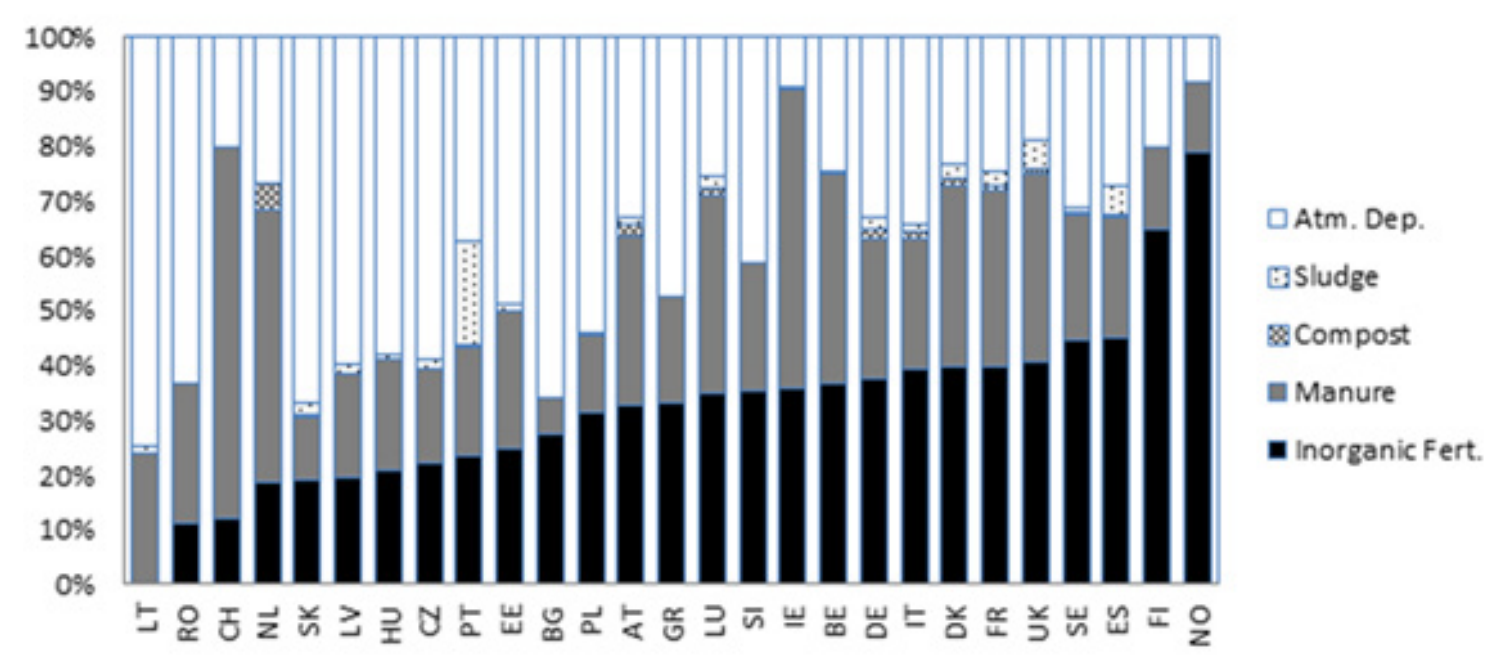

Figure 2.5 Contribution of different sources of Cd to arable land in EU Member States and associated countries (de Vries et al., 2016). 


\section{Conclusions \& recommendations}

\subsection{Conclusions}

How relevant/actual are current levels of Cd in food across EU in view of Cd intake? Does the regional differentiation in $\mathrm{Cd}$ in soil reflect regional differences in $\mathrm{Cd}$ in food?

- At present, the average weighted lifetime exposure to $\mathrm{Cd}$ (Mean Adjusted Average of $2.04 \mu \mathrm{g} \mathrm{Cd} / \mathrm{kg}$ b.w. per week) is within EFSA's conservative TWI levels. Although WHO/FAO concluded that adverse effects are unlikely to occur in an individual with current dietary exposure, Cd levels in food products result in an average exposure of infants (MB Mean of $2.74 \mu \mathrm{g} \mathrm{Cd} / \mathrm{kg} \mathrm{b} . \mathrm{w}$. per week) and the $95^{\text {th }}$ percentile exposure for adults (MB $95^{\text {th }}$ percentile of $3.09 \mu \mathrm{g} \mathrm{Cd} / \mathrm{kg} \mathrm{b.w.} \mathrm{per} \mathrm{week)} \mathrm{in} \mathrm{excess} \mathrm{of} \mathrm{the}$ TWI. Attention for Cd levels in food, therefore, is relevant and options to reduce such levels should be explored.

- The regional pattern of total $\mathrm{Cd}$ levels in soils is still largely dominated by geological factors on a European level, and have resulted in significant regional variations in $\mathrm{Cd}$ soil levels, ranging from $0.6 \mathrm{mg} \mathrm{Cd} / \mathrm{kg}$ (e.g. in Ireland) to $0.07 \mathrm{mg} \mathrm{Cd} / \mathrm{kg}$ (e.g. Portugal). Inputs from atmospheric deposition (traffic), inorganic and organic fertiliser application, and regional inputs from industry, amongst other factors, however, have had a clear impact on the Cd balance in large areas across the EU during the last four to five decades. Regionally, this has resulted in a considerable build-up of $\mathrm{Cd}$ levels in soil both in arable-, as well as natural soils, thus, leading to a further differentiation of $\mathrm{Cd}$ levels in soil across the EU. The EFSA's current exposure calculations were based on average Cd levels in food products across the EU. The contribution of products related to the variability of $\mathrm{Cd}$ across EU soils warrants a more in-depth analysis.

- It is not the total Cd levels, but rather the bioavailable Cd levels that determine the uptake by crops, particularly soil factors, such as $\mathrm{pH}$, organic matter content and clay content. These soil factors also demonstrate regional variations. At present, it is unclear to what extent such factors affect the levels of $\mathrm{Cd}$ in food products. These differences should also be considered.

- The quality of food products is however not directly linked to Cd levels in soil alone. The main reasons for this include the import of relevant products, consumption of non-soil related (sea)food, mixing and food processing, amongst other factors.

Is there an explicit link between levels of Cd in soil and Cd in food products and how does that affect human risk assessment?

- It is estimated that approximately $54 \%$ of the total intake of Cd via food is related to Cd levels in the soil. This is likely to be an underestimation, since the sum of some small other food groups can contribute for another $25 \%$ of the total exposure.

- From the crops that contribute to the aforementioned $54 \%$, three food groups seem most relevant: cereals, vegetables and potato.

- For human risk assessment that means that scenarios (e.g. based on different Cd loads to arable soils) can be compared, even if only in a relative way, in terms of increased exposure rates.

- The extent, to which the intake via the remaining non-soil related food products can be regulated is unclear, since the quality and amounts consumed of products in this group differ widely.

If this link between soil Cd and levels of Cd in crops exist, to what extent differ food crops (e.g. potato, wheat, rice) and food groups found to contribute significantly to human exposure in the EFSA evaluation? And: How do other soil factors affect this?

- Food groups differ in terms of quality (Cd content); this difference is due to plant-specific-response to the $\mathrm{Cd}$ in soil. Variability within one crop type is related to both variability in the Cd content in soil, as well as, albeit less strongly, soil properties including $\mathrm{pH}$, organic matter and clay content. 
- Current models can predict Cd levels in crops reasonably well, within a factor of 2 to 3 or less (for wheat).

- The variability in Cd uptake between varieties of single crops is significant, resulting in differences in Cd uptake of a factor of 3 to 10 between varieties. Current soil-based Cd predictions in crops do not take into account crop varieties.

- The ultimate exposure not only depends on the Cd content in crops and the variation within them, but also by the amount consumed.

Are current EFSA food groups and levels of Cd therein in agreement with predicted levels by current soil-crop models?

- The analysis presented in this study illustrates that current EFSA food groups are not all predicted by current soil-crop models. However, we can still analyse for specific food groups that are representing crop-based foods if levels of $\mathrm{Cd}$ therein measured upon food analysis are in agreement with predicted levels by current soil-crop models.

- To this end, Table 2.7 presents an overview of the median Cd concentrations for (sub) food categories, for which the available soil-models also provide Cd levels, enabling a comparison of the levels detected in food to those predicted by the soil-based models to be present in the respective crops. Given the wide range of different food products contributing to the Cd exposure when estimated based on food levels and dietary food consumption patterns, this comparison obviously only includes a limited number of food products that focus on crop based food (sub)categories. For Cd exposure, these crop-based food categories may contribute significantly to human exposure, but do not represent the full intake of $\mathrm{Cd}$ from the diet given that $\mathrm{Cd}$ appears to be ubiquitously present all over food chain.

- The opinion that EFSA published in 2012 presents the levels in a different format using also different food categories, and presenting only LB, MB and UB levels. Table 2.2 provides an overview of Cd levels in some relevant crop-related food categories, as presented in the later EFSA opinion (EFSA 2012).

The comparison provides an initial answer to the question of if levels of $\mathrm{Cd}$ in at least some food groups are in agreement with predicted levels by current soil-crop models

What would be the effect of different Cd levels in soil for overall human intake of Cd taking all food groups considered by EFSA into account?

The direct relationship between levels of $\mathrm{Cd}$ in soil and the resultant exposure via intake of crop-based food products is affected by several factors listed above (import/processing and other factors). Nevertheless, we estimate that a considerable (at least 55\%) part of the food consumption can be related to crops grown on soil in the EU. A subsequent initial assessment of the impact of changes in soil $\mathrm{Cd}$ levels and the resultant impact on exposure indicates that a reduction of soil Cd levels by $50 \%$ would result in a decrease of the average weekly intake of adults of 1.7 to $1.4 \mu \mathrm{g} \mathrm{Cd} / \mathrm{kg} \mathrm{b.w}$. (18\% reduction). For children the reduction of the soil Cd levels of $50 \%$ result in a decrease of the average weekly intake of 3.96 to $3.26 \mu \mathrm{g} \mathrm{Cd} / \mathrm{kg} \mathrm{b.w.} \mathrm{(18 \%} \mathrm{reduction),} \mathrm{which} \mathrm{is} \mathrm{still} \mathrm{above} \mathrm{the} \mathrm{suggested} \mathrm{TWI}$ of $2.5 \mu \mathrm{g} / \mathrm{kg}$ b.w. per week. These rough calculations show that a $50 \%$ decrease of the soil Cd content alone is not enough to reach the TWI for children.

Furthermore, the average annual inputs of fertilisers to agricultural soils are in the order of one to three grams/ha/yr. At a Cd level in soil of $0.4 \mathrm{mg} / \mathrm{kg}$, assuming a rooting zone of $20 \mathrm{~cm}$ and bulk density of $1.2 \mathrm{~kg} / \mathrm{L}$, this amounts to a total Cd pool of approx. $960 \mathrm{gram} / \mathrm{ha}$. Therefore, reducing the $\mathrm{Cd}$ load by fertiliser would have a very minor effect on the $\mathrm{Cd}$ pool during the first few decades, which will limit or delay the desired impact (i.e. a reduction of Cd levels in crops) on crop quality substantially.

These basic calculations suggest that limits on $\mathrm{Cd}$ in fertilisers, as a measure for addressing current health concerns, will only achieve minor results over a very long timescale. Therefore, other more immediate policy measures would appear to be more appropriate. Again, local- and regional variabilities in soil conditions, Cd levels in soil and application rates are such that the impact of such measures can also vary. On average though, it can be concluded that a reduced load from fertilisers will not or only reduce Cd levels in soils over long time scales (20 - 50 years). Due to the limited 
outputs of Cd via uptake and, for most soils, leaching compared to the $\mathrm{Cd}$ pool in soil, even a reduction of the Cd load from mineral phosphate fertilisers to zero, would require a very long timescale ( $>10-20$ years) to achieve a quantifiable reduction in soil Cd which in turn would have a proportionately even less significant impact on the Cd content of food derived from EU soils.

The ultimate impact of a reduced Cd load to soil however on Cd levels in major crop groups, and, hence, the intake of $\mathrm{Cd}$ via food, has not yet been quantified in detail. Based on current knowledge on the relation between Cd levels in soil and those in crops, it is, however, likely that the reduction in Cd crop level relative to changes in Cd levels in soil is small. Again, this has not been quantified on a regional- or even a national scale.

A more in-depth analysis of how levels of $\mathrm{Cd}$ in soil change as a result of revised (fertiliser) legislation is beyond the scope of this assessment, but results indicate that if such revisions lead to reduced (or increased) Cd levels in soil, exposure is reduced (or increased); but the response appears to be slow and non-linear, i.e. a 50\% reduction in soil $\mathrm{Cd}$ level will neither lead to a $50 \%$ reduction in Cd levels in crops (i.e. the response in crops is less than $50 \%$ reduction), nor in a $50 \%$ reduction in exposure.

As stated previously, in areas with elevated Cd levels in soil, or conditions that promote Cd uptake by crops (low pH, low organic matter content), limits on $\mathrm{Cd}$ in fertilisers may have a proportionately more significant impact on the exposure. This would suggest either retaining the current variations in national limits applied by EU Member States to suit their different national conditions, or, as that would be incompatible with establishing harmonised regulations across a single market, it could support a calibrated approach based on fertiliser application rates should be applied, taking into account the differences in local soil conditions (for example, on the lines of the approaches already adopted in Canada and New Zealand).

The overviews presented above illustrate that although crop-derived food products including wheat, potato and vegetables provide major contributions to current $\mathrm{Cd}$ intake levels, the contribution of nonsoil related food products in other food categories also contribute to the dietary intake. Here, we distinguish between two specific groups: i). food products not related to the quality of soil in the EU including sea food, imported products (e.g. cocoa beans) and ii). food products indirectly related to the quality of soil including meat, milk and other animal products. In the present estimation of the total percentage of soil-related crops, the latter category (ii) was included, whereas category i was not included.

Based on the EFSA reports, it can be estimated that food products directly or indirectly (category ii products) related to $\mathrm{Cd}$ in food crops contribute up to $54 \%$ of the total $\mathrm{Cd}$ intake via food. This implies that even though other food categories than crop-derived food products will contribute to the daily $\mathrm{Cd}$ intake, reduction of $\mathrm{Cd}$ levels in crops will contribute to a reduction of daily exposure.

A full analysis of the impact of changes in the Cd content in soil that could result from proposed fertiliser regulations on Cd levels in food crops, food products and the resulting human intake of $\mathrm{Cd}$ also taking into account that approximately $50 \%$ is not related to soil Cd levels- is beyond the scope of this report, but is clearly required to assess to what extent such regulations (and at what level of Cd in fertilisers) are effective. 


\subsection{Recommendations and uncertainties}

In this section, we point out a few issues that are relevant, either in relation to the assessment of the exposure, or that are required to acquire more insight into the relation between the impact of the proposed regulation of $\mathrm{Cd}$ in fertiliser and impact on soil, crops and ultimately, exposure of humans resulting from intake of food.

- Preliminary calculations using the link between soil quality, crop quality and exposure, suggest that dietary exposure of $\mathrm{Cd}$ is $50 \%$ related to the quality (i.e. Cd content) in EU soil. The contribution from non-soil related food products is poorly defined, and more information is needed on the type of food products, origin and impact on the exposure in order to assess to what degree this can be controlled via regulation.

- To address the question of whether or not a regional (country) policy is more effective than a common EU regulation to reduce exposure, a better definition of the influence of soil conditions and their variability on $\mathrm{Cd}$ uptake in crops is required. This requires further development and validation of soil crop relationships that consider differences in climate, crop type and soil conditions

- As shown in Figure 1.1 in the introduction, the relation between $\mathrm{Cd}$ inputs to soils on one hand and dietary intake of $\mathrm{Cd}$ on the other depends upon a series of relationships/processes. In this report, we analyse only a limited number of relations that focus on the relationship between dietary exposure and soils. It does not explore the effect of decreasing Cd contents in fertilisers, and the resultant impact on the $\mathrm{Cd}$ content in soils and their dynamics (in time), or the ultimate effect of the proposed reductions in the $\mathrm{Cd}$ content in fertiliser on dietary intake of $\mathrm{Cd}$

- At present, it is not clear for all food crops (or food groups as defined by EFSA) to what extent soil properties ( $\mathrm{Cd}$ content, $\mathrm{pH}$, organic matter etc.) control the level of $\mathrm{Cd}$ in crops or if additional factors also play a role?

- At present, models are capable of predicting the response of crops to changes in input. However, a step from crop quality (in terms of Cd content) to quality of food products that takes into account trade and processing, is not yet accounted for.

- The potential of using different crop varieties to reduce dietary intake of Cd does not yet seem to be fully explored. More information is needed on the ranges of Cd levels in main crop varieties as an effective way to reduce exposure. 


\section{References}

Abraham, E., Cavanagh, J., Wood, P., Pearson, A. \& Mladenov, P. 2016. Cadmium in New Zealand's agriculture and food systems. In: Integrated nutrient and water management for sustainable farming. (Eds L.D. Currie and R. Singh).

Adams, M. L., Zhao, F. J., McGrath, S. P., Nicholson, F. A. \& Chambers, B. J. 2004. Predicting Cadmium Concentrations in Wheat and Barley Grain Using Soil Properties. Journal of Environmental Quality, 33, 532-541.

Adamse, P., Driessen, J. J. M., de Jong, J., van Polanen, A., van Egmond, J. \& Jongbloed, A. W. 2009. Trendanalyse zware metalen in diervoeder(grondstoffen). Rikilt-WUR 2009.019, Wageningen.

Alexander, P. D., Alloway, B. J. \& Dourado, A. M. 2006. Genotypic variations in the accumulation of $\mathrm{Cd}, \mathrm{Cu}, \mathrm{Pb}$ and $\mathrm{Zn}$ exhibited by six commonly grown vegetables. Environmental Pollution, 144, 736-745.

Alexieva, D., Chobanova, S. \& Ilchev, A. 2007. Study on the level of heavy metal contamination in feed materials and compound feed for pigs and poultry in bulgaria Trakia Journal of Sciences, 5, 61-66.

Arnich, N., Sirot, V., Rivière, G., Jean, J., Noël, L., Guérin, T. \& Leblanc, J. C. 2012. Dietary exposure to trace elements and health risk assessment in the 2nd French Total Diet Study. Food and Chemical Toxicology, 50, 2432-2449.

Becker, W., Jorhem, L., Sundström, B. \& Grawé, K. P. 2011. Contents of mineral elements in Swedish market basket diets. Journal of Food Composition and Analysis, 24, 279-287.

Belon, E., Boisson, M., Deportes, I. Z., Eglin, T. K., Feix, I., Bispo, A. O., Galsomies, L., Leblond, S. \& Guellier, C. R. 2012. An inventory of trace elements inputs to French agricultural soils. Science of the Total Environment, 439, 87-95.

Bonten, L. T. C., Groenenberg, J. E., Meesenburg, H. \& De Vries, W. 2011. Using advanced surface complexation models for modelling soil chemistry under forests: Solling forest, Germany. Environmental Pollution, 159, 2831-2839.

Brus, D. J., De Gruijter, J. J. \& Römkens, P. F. A. M. 2005. Probabilistic quality standards for heavy metals in soil derived from quality standards in crops. Geoderma, 128, 301-311.

Chaudri, A. M., Zhao, F. J., McGrath, S. P. \& Crosland, A. R. 1995. The cadmium content of British wheat grain. Journal of Environmental Quality, 24, 850-855.

Crout, N. M. J., Beresford, N. A., Dawson, J. M., Soar, J. \& Mayes, R. W. 2004. The transfer of 73As, $109 \mathrm{Cd}$ and $203 \mathrm{Hg}$ to the milk and tissues of dairy cattle. Journal of Agricultural Science, 142, 203-212.

CSTEE 2002. Scientific Committee on Toxicity, Ecotoxicity and the Environment Brussels, C2/AST/csteeop/Cadmium in fertilizers 24092002/D(02).

de Vries, W., Kros, J. \& Römkens, P. F. A. M. 2016. Methodology to assess dynamics in nitrogen, phosphorus and cadmium concentrations over time in response to changed inputs. EEA report in preparation.

de Vries, W. \& McLaughlin, M. J. 2013. Modeling the cadmium balance in Australian agricultural systems in view of potential impacts on food and water quality. Science of the Total Environment, 461-462, 240-257.

de Vries, W., Römkens, P. F. \& Schütze, G. 2007. Critical soil concentrations of cadmium, lead, and mercury in view of health effects on humans and animals. In: Reviews of Environmental Contamination and Toxicology. pp. 91-130.

de Vries, W., Römkens, P. F. A. M., Bonten, L. T. C., Rietra, R. P. J. J., Ma, W. C. \& Faber, J. H. 2008. De invloed van bodemeigenschappen op kritische gehalten voor zware metalen en organische microverontreinigingen in de bodem, Alterra, Wageningen.

de Vries, W., Römkens, P. F. A. M., Kros, H., Voogd, J. C., Schröder, C. \& Aksoy, E. 2014. Field-scale balances of nitrogen, phosphorus, copper, zinc, cadmium and lead, and the impacts of policies on those balances. Task 182_2_1 "Impact of policy changes on net nutrient \& contaminant inputs ". 
Domingo, J. L. 2011. Influence of cooking processes on the concentrations of toxic metals and various organic environmental pollutants in food: A review of the published literature. Critical Reviews in Food Science and Nutrition, 51, 29-37.

Dowdy, R. H., Bray, B. J. \& Goodrich, R. D. 1983. Trace metal and mineral composition of milk and blood from goats fed silage produced on sludge-amended soil. Journal of Environmental Quality, 12, 473-478.

Eckel, H., Roth, U., Döhler, U. \& Schultheiß, U. 2008. Assessment and reduction of heavy metal input into agro-ecosystems, in: Trace elements in animal production systems. Schlegel,P. et al. (ed).

EFSA 2004. Opinion of the Scientific Panel on Contaminants in the Food Chain on a request from the Commission related to cadmium as undesirable substance in animal feed (Question NEFSA-Q2003-033) Adopted on 2 June 2004. The EFSA Journal, 72, 1-24.

EFSA 2009. European Food Safety Authority. Cadmium in food - Scientific opinion of the Panel on Contaminants in the Food Chain. EFSA Journal, 7, n/a-n/a.

EFSA 2012. European Food Safety Authority. Cadmium dietary exposure in the European population. EFSA Journal, 10, n/a-n/a.

EPA, U. S. 2011. Exposure Factors Handbook 2011 U.S. Environmental Protection Agency, Washington, DC, EPA/600/R-09/052F, 2011.

EU 2003. Regulation (EC) No 2003/2003 of the European Parliament and of the Council of 13 October 2003 relating to fertilisers

EU 2006. Commission Regulation (EC) No 1881/2006 of 19 December 2006 setting maximum levels for certain contaminants.

EU 2016. Circular economy package. COM(2016) 157 final. ANNEXES 1 to 5. ANNEXES to the Proposal for a regulation of the European Parliament and of the Council laying down rules on the making available on the market of CE marked fertilising products and amending Regulations (EC) No 1069/2009 and (EC) No 1107/2009. Brussels, 17.3.2016.

FDA 2007. Total Diet Study Statistics on Element Results., College Park, MD.

FDA 2016. Total Diet Study Elements Results Summary Statistics Market Baskets 2006 through 2011.

FEFAC 2014. Feed\&Food. Statistical yearbook 2014. In., http://www.fefac.eu/files/65464.pdf.

Ferrari, P., Arcella, D., Heraud, F., Cappé, S. \& Fabiansson, S. 2013. Impact of refining the assessment of dietary exposure to cadmium in the European adult population. Food Additives and Contaminants - Part A Chemistry, Analysis, Control, Exposure and Risk Assessment, 30, 687-697.

Franz, E., Römkens, P., van Raamsdonk, L. \& Van Der Fels-Klerx, I. 2008. A chain modeling approach to estimate the impact of soil cadmium pollution on human dietary exposure. Journal of Food

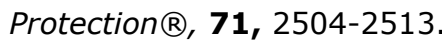

Freistaat Sachsen 2008. Schwermetalle in Dungemitteln, Sachsische Landesanstalt fur Landwirtschaft.

Guttieri, M. J., Seabourn, B. W., Liu, C., Baenziger, P. S. \& Waters, B. M. 2015. Distribution of Cadmium, Iron, and Zinc in Millstreams of Hard Winter Wheat (Triticum aestivum L.). Journal of Agricultural and Food Chemistry, 63, 10681-10688.

Ingwersen, J. \& Streck, T. 2005. A regional-scale study on the crop uptake of cadmium from sandy soils. Journal of Environmental Quality, 34, 1026-1035.

Ingwersen, J. \& Streck, T. 2006. Modeling the environmental fate of cadmium in a large wastewater irrigation area. Journal of Environmental Quality, 35, 1702-1714.

Jorhem, L., Sundström, B. \& Engman, J. 2001. Cadmium and other metals in Swedish wheat and rye flours: Longitudinal study, 1983-1997. Journal of AOAC International, 84, 1984-1992.

Koopmans, G. F., Römkens, P. F. A. M., Fokkema, M. J., Song, J., Luo, Y. M., Japenga, J. \& Zhao, F. J. 2008. Feasibility of phytoextraction to remediate cadmium and zinc contaminated soils. Environmental Pollution, 156, 905-914.

Kubo, K., Watanabe, Y., Oyanagi, A., Kaneko, S., Chono, M., Matsunaka, H., Seki, M. \& Fujita, M. 2008. Cadmium concentration in grains of Japanese wheat cultivars: Genotypic difference and relationship with agronomic characteristics. Plant Production Science, 11, 243-249.

Kurz, H. 1999. Selection of cultivars to reduce the concentration of cadmium and thallium in food and fodder plants. Journal of Plant Nutrition and Soil Science, 162, 323-328.

Lado, L. R., Hengl, T. \& Reuter, H. I. 2008. Heavy metals in European soils: A geostatistical analysis of the FOREGS Geochemical database. Geoderma, 148, 189-199.

Leblanc, J. C., Guérin, T., Noël, L., Calamassi-Tran, G., Volatier, J. L. \& Verger, P. 2005. Dietary exposure estimates of 18 elements from the 1st French Total Diet Study. Food Additives and Contaminants, 22, 624-641. 
Linden, A., Olsson, I. M., Bensryd, I., Lundh, T., Skerfving, S. \& Oskarsson, A. 2003. Monitoring of cadmium in the chain from soil via crops and feed to pig blood and kidney. Ecotoxicology and Environmental Safety, 55, 213-222.

McLaughlin, M. J., Smolders, E., Degryse, F. \& Rietra, R. 2011. Uptake of metals from soil into vegetables. In: Dealing with contaminated sites. Springer, pp. 325-367.

National Research Council 2005. Mineral tolerance of animals, National Academies Press, Washington, DC.

Nicholson, F. A., Smith, S. R., Alloway, B. J., Carlton-Smith, C. \& Chambers, B. J. 2003. An inventory of heavy metals inputs to agricultural soils in England and Wales. Science of the Total Environment, 311, 205-219.

Noleppa, S. \& Cartsburg, M. 2013 Agricultural self-sufficiency of the European Union. Statistical evidence. Agripol research paper 2013-02.

Oliver, D. F., Gore, P. J., Moss, H. J. \& Tiller, K. G. 1993. Cadmium in wheat-grain and milling products from some Australian flour mills. Australian Journal of Agricultural Research, 44, 1-11.

Oliver, D. P., Gartrell, J. W., Tiller, K. G., Correll, R., Cozens, G. D. \& Youngberg, B. L. 1995. Differential responses of Australian wheat cultivars to cadmium concentration in wheat grain. Australian Journal of Agricultural Research, 46, 873-886.

Olsson, I. M., Eriksson, J., Öborn, I., Skerfving, S. \& Oskarsson, A. 2005. Cadmium in food production systems: A health risk for sensitive population groups. Ambio, 34, 344-351.

Perello, G., Martí-Cid, R., Llobet, J. M. \& Domingo, J. L. 2008. Effects of various cooking processes on the concentrations of arsenic, cadmium, mercury, and lead in foods. Journal of Agricultural and Food Chemistry, 56, 11262-11269.

Reimann, C., and M. Birke. 2010. Geochemistry of European Bottled Water. Borntraeger Science Publishers. ISBN 978-3-443-01067-6, 268pp.

Römkens, P. F. A. M., Brus, D. J., Guo, H. Y., Chu, C. L., Chiang, C. M. \& Koopmans, G. F. 2011. Impact of model uncertainty on soil quality standards for cadmium in rice paddy fields. Science of the Total Environment, 409, 3098-3105.

Römkens, P. F. A. M., Groenenberg, J. E., Rietra, R. P. J. J. \& de Vries, W. 2007. Onderbouwing LAC2006 waarden en overzicht van bodem-plant relaties ten behoeve van de Risicotoolbox : een overzicht van gebruikte data en toegepaste methoden, Alterra, Wageningen.

Sand, S. \& Becker, W. 2012. Assessment of dietary cadmium exposure in Sweden and population health concern including scenario analysis. Food and Chemical Toxicology, 50, 536-544.

SCHER 2015. (Scientific Committee on Health and Environmental Risks), SCHER Opinion on new conclusions regarding future trends of cadmium accumulation in EU arable soils.

27 November 2015.

Schultheiß, U., Döhler, H., Roth, U., Eckel, H., Goldbach, H., Kühnen, V., Wilcke, W., Uihlein, A., Früchtenicht, K. \& Steffens, G. 2003. Assessment of heavy metal flows in animal husbandry and development of a strategy to reduce heavy metal inputs into agro-ecosystems by animal manures, Forschungsbericht 29972 104, UBA-FB 000580, Texte 06/04, Berlin.

Schwarz, M. A., Lindtner, O., Blume, K., Heinemeyer, G. \& Schneider, K. 2014. Cadmium exposure from food: The German LExUKon project. Food Additives and Contaminants - Part A Chemistry, Analysis, Control, Exposure and Risk Assessment, 31, 1038-1051.

Six, L. \& Smolders, E. 2014. Future trends in soil cadmium concentration under current cadmium fluxes to European agricultural soils. Science of the Total Environment, 485-486, 319-328.

Smith, R. M., Leach, R. M., Muller, L. D., Griel Jr, L. C. \& Baker, D. E. 1991. Effects of long-term dietary cadmium chloride on tissue, milk, and urine mineral concentrations of lactating dairy cows. Journal of animal science, 69, 4088-4096.

Smolders, E. \& Six, L. 2013. Revisiting and updating the effect of phosphate fertilizers to cadmium accumulation in European agricultural soils, Leuven, Division Soil and Water Management, Heverlee, Belgium,.

Stevens, J. B. 1991. Disposition of toxic metals in the agricultural food chain. 1. Steady-state bovine milk biotransfer factors. Environmental Science and Technology, 25, 1289-1294.

Swartjes, F. A. 2011. Dealing with contaminated sites: from theory towards practical application, Springer Science \& Business Media.

UN 2010. Final review of scientific information on cadmium. version of December 2010, UNITED NATIONS ENVIRONMENT PROGRAMME, Chemicals Branch, DTIE. 
UNFCC 2007. National Inventory Submissions from 2007: http://unfccc.int/national_reports/ annex_i_ghg_inventories/national_inventories_submissions/items/4303.php. 11 september 2007. van der Fels-Klerx, I., Römkens, P., Franz, E. \& van Raamsdonk, L. 2011. Modeling cadmium in the feed chain and cattle organs. Biotechnology, Agronomy and Society and Environment, 15, 53-59.

Vreman, K., Vanderveen, N. G., Vandermolen, E. J. \& Deruig, W. G. 1986. Transfer of cadmium, lead, mercury and arsenic from feed into milk and various tissues of dairy-cows - chemical and pathological data. Netherlands Journal of Agricultural Science, 34, 129-144.

Vromman, V., Waegeneers, N., Cornelis, C., de Boosere, I., van Holderbeke, M., Vinkxd, C., Smolders, E., Huyghebaert, A. \& Pussemier, L. 2010. Dietary cadmium intake by the belgian adult population. Food Additives and Contaminants - Part A Chemistry, Analysis, Control, Exposure and Risk Assessment, 27, 1665-1673.

Waegeneers, N., Hoenig, M., Goeyens, L. \& De Temmerman, L. 2009. Trace elements in homeproduced eggs in Belgium: Levels and spatiotemporal distribution. Science of the Total Environment, 407, 4397-4402.

White, D. H. \& Finley, M. T. 1978. Uptake and retention of dietary cadmium in mallard ducks. Environmental Research, 17, 53-59.

Xiao, Y., Mignolet, C., Mari, J.-F. \& Benoît, M. 2014. Modeling the spatial distribution of crop sequences at a large regional scale using land-cover survey data: A case from France. Computers and Electronics in Agriculture, 102, 51-63.

Zhang, K., Wang, J., Yang, Z., Xin, G., Yuan, J., Xin, J. \& Huang, C. 2013a. Genotype variations in accumulation of cadmium and lead in celery (Apium graveolens L.) and screening for low Cd and $\mathrm{Pb}$ accumulative cultivars. Frontiers of Environmental Science and Engineering in China, 7, 85-96.

Zhang, K., Yuan, J., Kong, W. \& Yang, Z. 2013b. Genotype variations in cadmium and lead accumulations of leafy lettuce (Lactuca sativa L.) and screening for pollution-safe cultivars for food safety. Environmental Sciences: Processes and Impacts, 15, 1245-1255. 


\section{Annex 1 Soil-plant transfer functions}

Table A1.1 Soil-based predicted average Cd concentrations in crops products $(\mathrm{mg} / \mathrm{kg})$ in EU Member States.

\begin{tabular}{|c|c|c|c|c|c|c|c|c|c|c|}
\hline Member State & potato & endive & barley & carrot & wheat & spinach & leek & lettuce & tomato & radish \\
\hline AT & 0.08 & 0.87 & 0.05 & 0.43 & 0.10 & 0.78 & 0.06 & 0.58 & 0.42 & 0.41 \\
\hline $\mathrm{BE}$ & 0.10 & 0.97 & 0.06 & 0.44 & 0.12 & 0.94 & 0.09 & 0.70 & 0.47 & 0.51 \\
\hline BG & 0.04 & 0.48 & 0.03 & 0.28 & 0.07 & 0.41 & 0.01 & 0.24 & 0.35 & 0.25 \\
\hline $\mathrm{CH}$ & 0.06 & 0.68 & 0.05 & 0.37 & 0.09 & 0.59 & 0.03 & 0.41 & 0.36 & 0.36 \\
\hline $\mathrm{CZ}$ & 0.08 & 1.07 & 0.04 & 0.48 & 0.11 & 0.93 & 0.05 & 0.66 & 0.57 & 0.43 \\
\hline DE & 0.06 & 0.69 & 0.04 & 0.37 & 0.09 & 0.61 & 0.04 & 0.43 & 0.36 & 0.37 \\
\hline DK & 0.05 & 0.62 & 0.03 & 0.38 & 0.07 & 0.47 & 0.03 & 0.35 & 0.27 & 0.29 \\
\hline $\mathrm{EE}$ & 0.04 & 0.68 & 0.02 & 0.52 & 0.05 & 0.50 & 0.02 & 0.41 & 0.21 & 0.22 \\
\hline $\mathrm{EL}$ & 0.04 & 0.41 & 0.05 & 0.24 & 0.08 & 0.39 & 0.02 & 0.22 & 0.32 & 0.30 \\
\hline ES & 0.04 & 0.43 & 0.03 & 0.26 & 0.06 & 0.34 & 0.02 & 0.23 & 0.27 & 0.25 \\
\hline FI & 0.04 & 0.64 & 0.02 & 0.48 & 0.05 & 0.42 & 0.02 & 0.35 & 0.21 & 0.21 \\
\hline FR & 0.05 & 0.51 & 0.04 & 0.32 & 0.07 & 0.44 & 0.02 & 0.29 & 0.27 & 0.29 \\
\hline HR & 0.08 & 0.81 & 0.06 & 0.42 & 0.11 & 0.81 & 0.05 & 0.55 & 0.43 & 0.47 \\
\hline $\mathrm{HU}$ & 0.04 & 0.45 & 0.03 & 0.29 & 0.06 & 0.37 & 0.01 & 0.23 & 0.29 & 0.25 \\
\hline IE & 0.08 & 0.80 & 0.05 & 0.53 & 0.10 & 0.77 & 0.04 & 0.59 & 0.29 & 0.39 \\
\hline IT & 0.05 & 0.49 & 0.05 & 0.30 & 0.08 & 0.46 & 0.02 & 0.29 & 0.28 & 0.31 \\
\hline LI & 0.04 & 0.42 & 0.04 & 0.26 & 0.07 & 0.35 & 0.02 & 0.22 & 0.27 & 0.29 \\
\hline LT & 0.05 & 0.77 & 0.03 & 0.45 & 0.06 & 0.54 & 0.02 & 0.41 & 0.34 & 0.25 \\
\hline LU & 0.04 & 0.41 & 0.04 & 0.28 & 0.06 & 0.35 & 0.01 & 0.22 & 0.24 & 0.24 \\
\hline LV & 0.04 & 0.74 & 0.02 & 0.49 & 0.05 & 0.47 & 0.01 & 0.37 & 0.28 & 0.21 \\
\hline ME & 0.08 & 0.65 & 0.07 & 0.32 & 0.12 & 0.67 & 0.06 & 0.44 & 0.41 & 0.50 \\
\hline MK & 0.06 & 0.62 & 0.05 & 0.33 & 0.09 & 0.62 & 0.03 & 0.38 & 0.40 & 0.37 \\
\hline $\mathrm{NL}$ & 0.07 & 0.81 & 0.05 & 0.47 & 0.09 & 0.67 & 0.07 & 0.56 & 0.31 & 0.38 \\
\hline NO & 0.04 & 0.65 & 0.02 & 0.41 & 0.06 & 0.45 & 0.02 & 0.34 & 0.27 & 0.24 \\
\hline $\mathrm{PL}$ & 0.08 & 0.89 & 0.04 & 0.38 & 0.10 & 0.76 & 0.13 & 0.59 & 0.46 & 0.43 \\
\hline PT & 0.03 & 0.58 & 0.02 & 0.32 & 0.05 & 0.35 & 0.02 & 0.24 & 0.35 & 0.20 \\
\hline RO & 0.06 & 0.78 & 0.04 & 0.41 & 0.09 & 0.70 & 0.03 & 0.47 & 0.43 & 0.34 \\
\hline SE & 0.06 & 0.88 & 0.03 & 0.48 & 0.07 & 0.60 & 0.05 & 0.51 & 0.33 & 0.32 \\
\hline SI & 0.13 & 1.29 & 0.07 & 0.57 & 0.14 & 1.39 & 0.09 & 1.07 & 0.56 & 0.60 \\
\hline SK & 0.08 & 1.00 & 0.04 & 0.43 & 0.10 & 0.87 & 0.06 & 0.62 & 0.56 & 0.43 \\
\hline TR & 0.02 & 0.20 & 0.03 & 0.16 & 0.04 & 0.16 & 0.00 & 0.08 & 0.18 & 0.17 \\
\hline UK & 0.06 & 0.63 & 0.04 & 0.46 & 0.08 & 0.58 & 0.02 & 0.43 & 0.25 & 0.30 \\
\hline average & 0.06 & 0.64 & 0.04 & 0.36 & 0.08 & 0.56 & 0.04 & 0.39 & 0.34 & 0.33 \\
\hline $\min$ & 0.02 & 0.20 & 0.02 & 0.16 & 0.04 & 0.16 & 0.00 & 0.08 & 0.18 & 0.17 \\
\hline $\max$ & 0.13 & 1.29 & 0.07 & 0.57 & 0.14 & 1.39 & 0.13 & 1.07 & 0.57 & 0.60 \\
\hline factor & 7 & 6 & 4 & 3 & 3 & 9 & 28 & 13 & 3 & 3 \\
\hline
\end{tabular}




\section{Annex 2 Effect of different Cadmium soil levels for Cadmium in crop products}

Table A2.1 Soil-based predicted average Cd concentrations in crops products $(\mathrm{mg} / \mathrm{kg})$. Calculated is the average of all spatial units in EU Member States (see Paragraph 2.3.3).

\begin{tabular}{lcccccccccc}
\multicolumn{1}{c}{ Cd soil } & potato & endive & barley & leek & radish & lettuce & spinach & wheat & tomato & carrot \\
\hline $1.0 \times$ Current & 0.050 & 0.631 & 0.036 & 0.030 & 0.294 & 0.364 & 0.501 & 0.071 & 0.307 & 0.373 \\
\hline $0.5 \times$ current & 0.029 & 0.422 & 0.024 & 0.011 & 0.185 & 0.202 & 0.294 & 0.046 & 0.215 & 0.305 \\
\hline & & & & & & & & & & \\
\hline factor & 0.57 & 0.67 & 0.67 & 0.38 & 0.63 & 0.55 & 0.59 & 0.65 & 0.70 & 0.82 \\
\hline
\end{tabular}




\section{Annex 3 Reflection on the approach by Smolders and Six (2013)}

Here, we discuss some of the issues listed in Chapter 2 regarding the approach used to calculate the changes in the Cd balance at EU level.

A simple mass balance for Europe can be a good average if many relations are near to linear.

If relationships between the soil and crop quality ( $\mathrm{Cd}$ content) are linear, then the variation between countries and crops with high phosphate fertilisation rates, or high crop off-takes are compensated for by countries with low application rates or low production levels. In the mass balance approach, leaching is the most important output. Leaching is modelled using regression models, in which Cd content in soil, soil $\mathrm{pH}$, and soil organic carbon are the explaining factors. However, leaching of $\mathrm{Cd}$ from soil is not linearly related to the Cd content (and other factor) for soils. Leaching predominantly occurs in polluted soils, and very lightly in non-polluted soils. Due to this non-linearity between soil and solution $\mathrm{Cd}$ content, an average Cd content in a soil is not likely to be a good estimator for leaching of Cd. The validity of the assumption of Smolders and Six (2013) can be checked by performing calculations for different units (cropping systems, soil types, countries, climate), and by comparing the calculated average with the average of Smolders and Six (2013). In addition, besides leaching, Cd crop off-take is neither linearly related to the Cd content nor to the other soils factors.

In this study, the impact of the non-linearity of both soil-crop and soil-solution relationships on the Cd balance, as compared to the balance based on-average-linear relationships cannot be quantified. A suggested follow-up can be to calculate both crop off-take and leaching at a EU level using the previously described Cd map of Europe (de Vries et al., 2014), in which the whole EU (EU27) is described by a total of 46,650 spatial units (a unique combination of soil type, administrative region, slope class and altitude).

The effect of using mineral phosphate fertilisers on Cd accumulation in soils.

As such, the use of mineral fertilisers contributes significantly to the total load of Cd in soils (Figure 2.5) and is the subject of research. The total input by fertilisers and the variation of this across the EU, then depends on both the quantity of fertilisers applied and the quality of them. Six and Smolders (2014) used application rates for phosphate fertilisers that are average application rates for cereals and potato ( $21 \mathrm{~kg}$ and $45 \mathrm{~kg} \mathrm{P}_{2} \mathrm{O}_{5} \mathrm{ha}^{-1}$ respectively) in the EU. The average application rate for mineral phosphate fertilisers is given as is $14 \mathrm{~kg} \mathrm{P}_{2} \mathrm{O}_{5} \mathrm{ha}^{-1}$ in agricultural soils and $22 \mathrm{~kg}_{2} \mathrm{O}_{5} \mathrm{ha}^{-1}$ for arable soils. It is not clear why Six and Smolders (2014) chose only three scenarios for land use: 1). Monocrop with wheat $\left(21 \mathrm{~kg} \mathrm{P}_{2} \mathrm{O}_{5} \mathrm{ha}^{-1}\right)$, 2). Two-year cereals and one year potato rotation $\left(29 \mathrm{~kg} \mathrm{P}_{2} \mathrm{O}_{5}\right.$ $\mathrm{ha}^{-1}$ ), and 3). Monocrop with potatoes (45 kg $\mathrm{P}_{2} \mathrm{O}_{5} \mathrm{ha}^{-1}$ ). Although 'arable soil', it is clearly stated in the title of this study, arable soil cannot be clearly distinguished from other agricultural soils when using scenarios for a period of 100 years. For example in the EU roughly $10 \%$ of the arable land is temporary grassland (Eurostat, cropping patterns).

For example, on the basis of aerial photos of France during 1992 to 2003 crop sequence patterns were analysed for the whole country. The major crop sequences in France are 1). Three-year crop rotation of 'wheat-barley-rapeseed', 2) A two-year crop rotation 'maize-wheat', 3) 'Rapeseed-wheat', 4). Monocultures of maize, wheat and barley, 5). Long-term fallow, temporary pasture, and 6). Sequences of different two-year rotations with the three-year rotation or one-year wheat (Xiao et al., 2014). It is clear that a simple crop sequence is not available. The scenario using $29 \mathrm{~kg} \mathrm{P}_{2} \mathrm{O}_{5} \mathrm{ha}^{-1}$ scenario, for a crop rotation of two-year cereals and one-year potatoes, should, therefore, be considered as a worse-case scenario. The monocrop scenario with potatoes ( $45 \mathrm{~kg} \mathrm{P}_{2} \mathrm{O}_{5} \mathrm{ha}^{-1}$ ) should not be considered, because this cropping system does not exist in Europe. It would be appropriate to include also other scenarios that include land use changes, or different application rates for mineral phosphate fertilisers. 
The input of $\mathrm{Cd}$ to soils is of major importance to calculate an appropriate Cd mass balance. Animal manure and aerial deposition are often considered to be important inputs of $\mathrm{Cd}$ onto agricultural land (Nicholson et al., 2003; (Belon et al., 2012) (Nicholson et al., 2003). A recent calculation for various EU Member States reveals that the contribution of mineral fertilisers to the total Cd load is also quite substantial, but at the same time can vary widely and ranges from 20 to $70 \%$ of the total Cd input (de Vries et al., 2016).

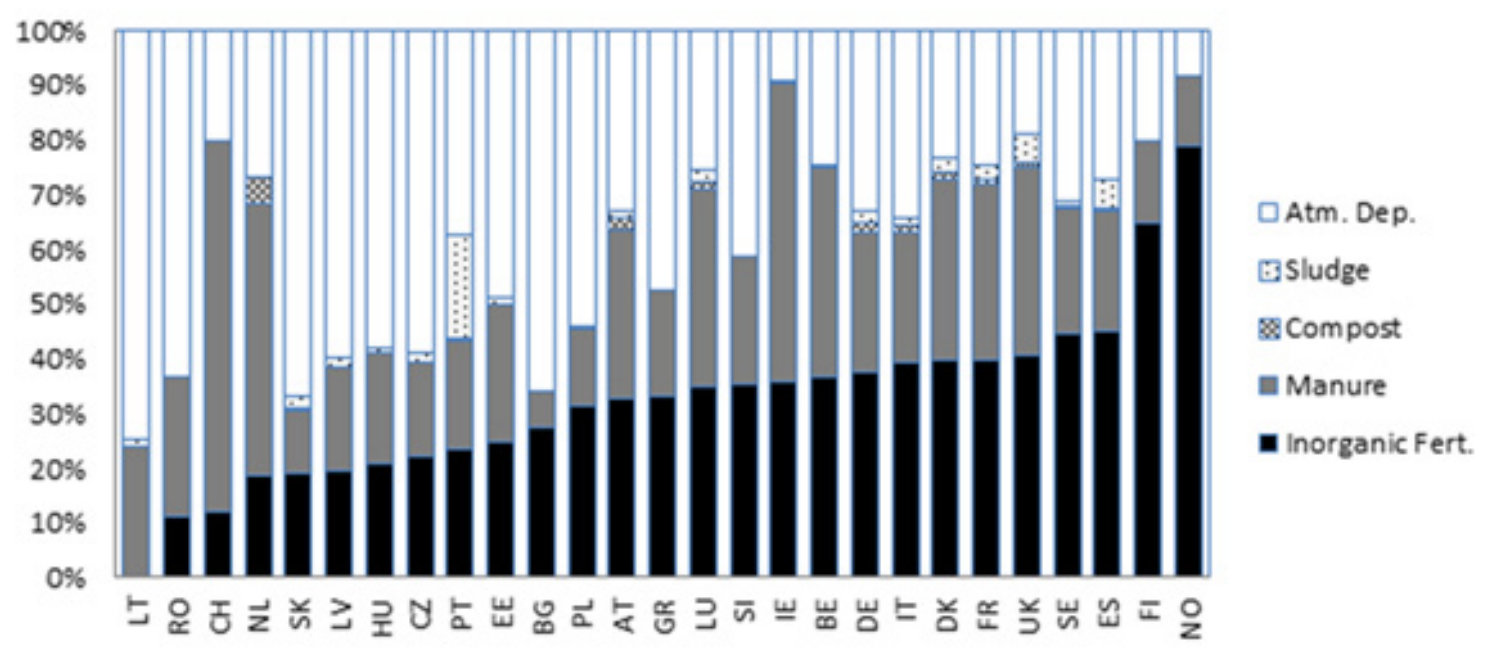

Figure A3.1 Contribution of different sources of Cd to arable land in EU member states and associated countries (de Vries et al., 2016).

Smolders and Six (2013), however, assumed that this flux of $\mathrm{Cd}$ is being recycled from soil to feed and from feed to manure. They assumed that only imported $\mathrm{Cd}$ in feed contributes as an input. They calculated this import on the basis of average $\mathrm{Cd}$ in cereals $\left(0.02-0.05 \mathrm{mg} \mathrm{Cd} \mathrm{kg}^{-1}\right.$ grain) and the imported amount of animal feed. This results in a low Cd input of $0.01 \mathrm{~g} \mathrm{Cd} \mathrm{ha}^{-1} \mathrm{y}^{-1}$ in Europe, which suggests that $\mathrm{Cd}$ input from imported feed is unimportant.

These assumptions can be tested by looking at farm balances at various scales, as these offer the opportunity to check the balance by measurements of $\mathrm{Cd}$ contents in manure and assuming a certain efficiency of feed conversion. There is not only import from feeds from outside the EU but also minerals (phosphate, zinc and copper minerals) are added to the feed which contain Cd, and there is corrosion of materials within the stable than end in the manure. For example, the assumption was tested for pigs on a regional scale at 37 Swedish farms. The average Cd contents of all inputs were determined and its contribution. Whilst concentrates contributed $15 \%$ to the amount of feed, its contribution to the $\mathrm{Cd}$ in feed was 53.2\% (Linden et al., 2003). Similarly, in German pig farms, 37\% of the Cd came from home grown feed and $11 \%$ came from animal feed from outside the farm (party imported from outside the EU), but in total, 52\% were inputs (minerals, stable corrosion, including water and bedding material) (Schultheiß et al., 2003). On dairy farms, the contribution of mineral feedstuffs, stable equipment and other stable inputs was $7 \%$ in total. The contribution of these mineral additives (including water and bedding material) on a German pig farm was estimated to be $0.23 \mathrm{~g} \mathrm{Cd} \mathrm{ha}^{-1} \mathrm{y}^{-1}$ (Eckel et al., 2008). These values are much higher than $0.01 \mathrm{~g} \mathrm{Cd} \mathrm{ha}^{-1} \mathrm{y}^{-1}$ (Table 2.8) and are specific for pig farms, but they show important contributions that were not taken account.

Looking in more detail to the data used reveals large differences. Smolders and Six (2013) estimate the import of animal feed at $3010^{9} \mathrm{~kg}$ per year and assume a Cd content based on cereal grains of 0.02-0.05 mg Cd kg-1 grain. However, imported animal feeds have been reported by the industry (FEFAC, 2014): in the period 2006-2014 at $4310^{9} \mathrm{~kg}$ per year. Imported feed consists of cereals, and other products. The contribution of cereals in the period 2006-2014 was only 25\% (FEFAC, 2014). 
Also EU Member States have reported Cd concentrations in forages and other feed materials (EFSA, 2004) to be $0.32 \mathrm{mg} \mathrm{Cd} \mathrm{kg}^{-1}$ dry matter in forages, and 0.06 to $0.41 \mathrm{mg} \mathrm{Cd} \mathrm{kg}^{-1}$ dry matter in various other feed materials (EFSA, 2004). Monitoring in the Netherlands shows that some animal feeds contain low levels of $\mathrm{Cd}$, such as grass, cereals and soya, but that some feeds contain high Cd levels. High contents have been found in animal feeds from poppy seed, sunflower seed, maize, fish meals and minerals. The median Cd content in complete, complementary and mineral feed were 0.069, 0.1 and $0.7 \mathrm{mg} \mathrm{Cd} \mathrm{kg}^{-1}$ respectively in 2003 (12\% moisture). Mineral mixtures contained mineral phosphates with a Cd content of 0.5-6 mg Cd kg ${ }^{-1} \mathrm{P}_{2} \mathrm{O}_{5}$ (Adamse et al., 2009). Average Cd contents in various compound feeds in the UK contained 0.12 to $0.39 \mathrm{mg} \mathrm{Cd} \mathrm{kg}^{-1} \mathrm{dm}$ (Nicholson et al., 2003). The average $\mathrm{Cd}$ content of feed and compound feed for pig and poultry in Bulgaria were 0.54 and 0.27 $\mathrm{mg} \mathrm{Cd} \mathrm{kg}^{-1}$ product respectively and $20 \%$ of the cases did not meet the European limit values (Alexieva et al., 2007). All these values for feed materials are higher than the value (0.02-0.05) used by Smolders and Six (2013), which suggest a better assessment is required for Cd in animal manure, as these data suggest that the contribution of animal manure, and imported feed, to Cd input to soils is higher. The import of animal feeds as compared to Smolders and Six (2013) and Cd content of various animal feed materials suggest a much higher contribution of imported Cd to the input to European soils.

In Table A3.1, an overview is given of the mass balance outcome as calculated by Smolders and Six (2013) using a generic approach and recent results from De Vries et al. (2016) and showing country averaged values of inputs, outputs and the resulting metal balance for $\mathrm{Cd}$ for arable soils. One striking difference is the calculated mean balance for $\mathrm{Cd}$ which is $-1.47 \mathrm{~g} / \mathrm{ha} / \mathrm{yr}$ as given by Smolders and Six (2013) versus a value of +0.65 calculated by De Vries et al. (2016). This difference can be largely related to the much larger leaching flux of $2.56 \mathrm{~g} / \mathrm{ha} / \mathrm{yr}$ by Smolders and Six (2013). Asides from the large difference in the leaching flux, the calculated median values of most fluxes (all inputs and crop uptake) are quite similar, despite differences in model approach and or assumptions and underlying data. Nevertheless, the large range in predicted fluxes, notably the variability in fertiliser load ( 0.08 to $1.32 \mathrm{~g} / \mathrm{ha} / \mathrm{yr}$ ) and leaching lead to large regional (here at country scale) differences in the net Cd balance. Clearly, such differences imply that proposed changes in fertiliser quality will have a pronounced regional impact as well.

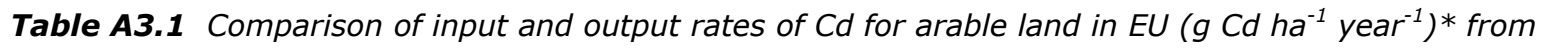
reference $A$ (de Vries et al., 2016) and B (Six \& Smolders, 2014).

\begin{tabular}{|c|c|c|c|c|c|c|c|c|c|c|}
\hline \multirow{3}{*}{ ref } & & \multicolumn{4}{|c|}{ Inputs } & \multicolumn{2}{|c|}{ Outputs } & \multirow[b]{3}{*}{ Inputs } & \multirow[b]{3}{*}{ Outputs } & \multirow[b]{3}{*}{ Balance } \\
\hline & & & & Comp & Atm & Plant & & & & \\
\hline & & manure & Fertiliser & +Sludge & dep & uptake & Leaching & & & \\
\hline A & Minimum & 0.08 & 0.08 & 0.00 & 0.16 & 0.01 & 0.07 & 0.76 & 0.15 & -4.05 \\
\hline A & Median & 0.25 & 0.62 & 0.04 & 0.42 & 0.22 & 0.54 & 1.39 & 0.71 & 0.65 \\
\hline A & Maximum & 1.00 & 1.32 & 0.49 & 0.91 & 0.98 & 6.05 & 2.55 & 6.38 & 1.43 \\
\hline B & Mean & 0.01 & 0.88 & 0.05 & 0.35 & 0.20 & 2.56 & 1.29 & 2.76 & -1.47 \\
\hline
\end{tabular}

* for only one cropping systems: arable (neglecting: rotation two years cereals one year potato, and potato monocrop), $36 \mathrm{mg} \mathrm{Cd} \mathrm{kg} \mathrm{P}_{2} \mathrm{O}_{5}{ }^{-1}$

Contribution and distribution of other soil amendments to the total Cd load.

As mentioned, the input of $\mathrm{Cd}$ to soils is of major importance to calculate an appropriate Cd mass balance. The contribution of $\mathrm{Cd}$ from lime and sludge are spread over the total agricultural area. Smolders and Six (2013) estimated the Cd input from lime on the basis of data from Sweden, France and Germany at $250 \mathrm{~kg} \mathrm{CaO} \mathrm{ha-1} \mathrm{yr}^{-1}$ containing $0.35 \mathrm{mg} \mathrm{Cd} \mathrm{kg} \mathrm{CaO}$ and resulting in $0.09 \mathrm{~g} \mathrm{Cd} \mathrm{ha}^{-1} \mathrm{yr}^{-}$ ${ }^{1}$. The contribution of lime is, therefore, relevant.

Smolders and Six (2013) did not used the liming data, which are available for all EU Member States for the years 2003-2015. These show a large variation between EU countries, for example, the use of agricultural lime in Sweden, France and Germany is 79, 40 and $199 \mathrm{~kg}^{\text {lime ha }}{ }^{-1} \mathrm{yr}^{-1}$ respectively and between arable land and grassland in EU, 128 and $16 \mathrm{~kg}$ lime ha ${ }^{-1} \mathrm{yr}^{-1}$ respectively (UNFCC, 2007). 
Lime is predominantly used on non-calcareous arable land. And sludge is predominantly used on arable land. This increases the importance of the Cd input from sludge and lime, as compared to mineral phosphate in arable land, of Smolders and Six (2013). Scenario calculations will improve by taking these variations in land use into account. The average $\mathrm{Cd}$ content in agricultural lime was recently reported to be $0.52 \mathrm{mg} \mathrm{Cd} \mathrm{kg}{ }^{-1}$ lime, and is in line with the value used by Smolders and Six (2013), but the Cd content in lime can show large regional variations (Freistaat Sachsen, 2008).

The four arguments above show that a simple mass balance for Europe is possibly not appropriate, as the use of an average structurally changes the outcome. The data used to calculate the mass balance are in some cases insufficient and can be improved. Most importantly, the scenarios used for land use, do not give an average for arable land but a worst-case scenario.

The validity of the leaching and dynamic modelling of $\mathrm{Cd}$ in EU soils has not been shown by Smolders and Six (Smolders \& Six, 2013; Six \& Smolders, 2014). Although, they have extensively tested the sensitivity of the model, a validation was not performed. Validation is possible by using historical series (Bonten et al., 2011; Abraham et al., 2016), or recalculating current soil Cd levels, as performed on a local scale in Germany (Ingwersen \& Streck, 2006), and a national scale for Australia (De Vries \& McLaughlin, 2013). 
Wageningen Environmental Research P.O. Box 47

6700 AA Wageningen

The Netherlands

T +31 (0)317480700

www.wur.nl/environmental-research

Wageningen Environmental Research Report 2784

ISSN 1566-7197
The mission of Wageningen University and Research is "To explore the potential of nature to improve the quality of life". Under the banner Wageningen University \& Research, Wageningen University and the specialised research institutes of the Wageningen Research Foundation have joined forces in contributing to finding solutions to important questions in the domain of healthy food and living environment. With its roughly 30 branches, 5,000 employees and 10,000 students, Wageningen University \& Research is one of the leading organisations in its domain. The unique Wageningen approach lies in its integrated approach to issues and the collaboration between different disciplines.

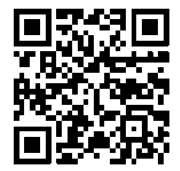




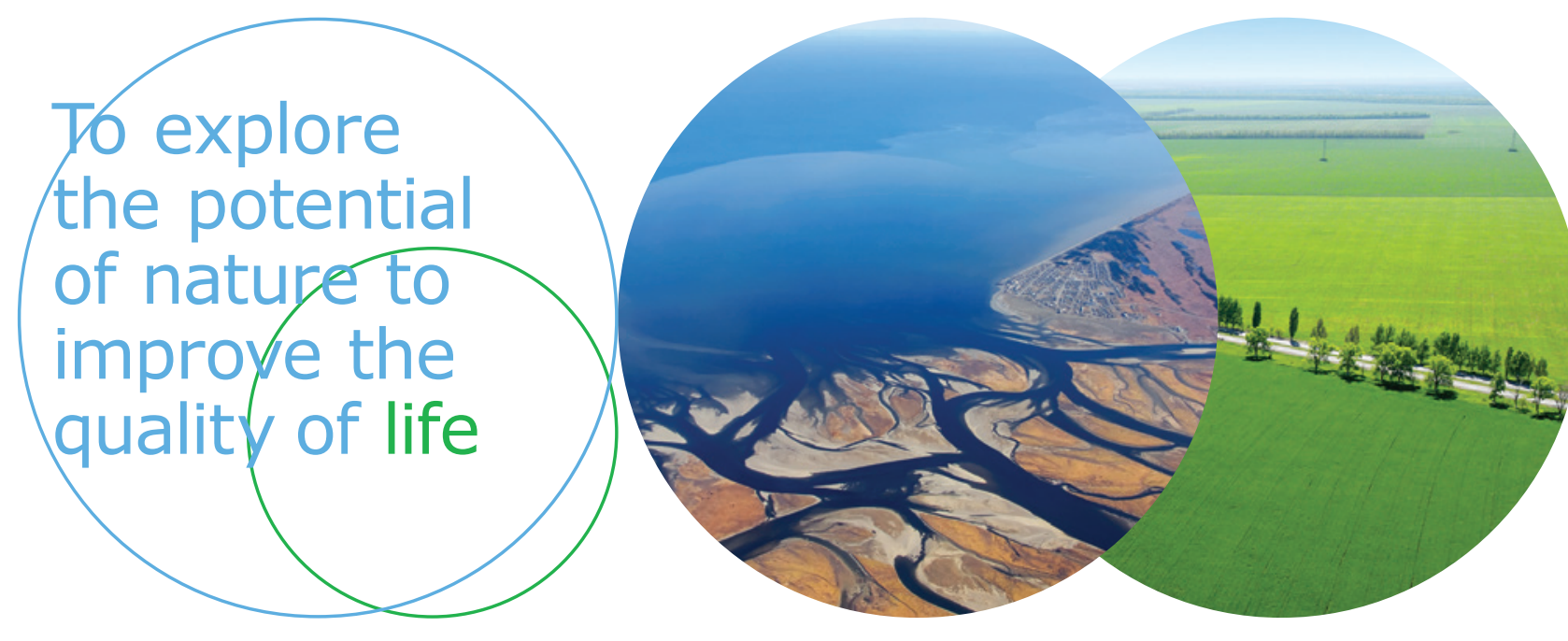

Wageningen Environmental Research P.O. Box 47

$6700 \mathrm{AB}$ Wageningen

The Netherlands

$\mathrm{T}+31(0) 317480700$

www.wur.eu/environmental-research

Report 2784

ISSN 1566-7197
The mission of Wageningen University and Research is "To explore the potential of nature to improve the quality of life". Under the banner Wageningen University \& Research, Wageningen University and the specialised research institutes of the Wageningen Research Foundation have joined forces in contributing to finding solutions to important questions in the domain of healthy food and living environment. With its roughly 30 branches, 5,000 employees and 10,000 students, Wageningen University \& Research is one of the leading organisations in its domain. The unique Wageningen approach lies in its integrated approach to issues and the collaboration between different disciplines. 